University of Nebraska - Lincoln

DigitalCommons@University of Nebraska - Lincoln

USDA Forest Service / UNL Faculty Publications U.S. Department of Agriculture: Forest Service -National Agroforestry Center

2012

Revisiting the homogenization of dammed rivers in the southeastern US

Ryan A. McManamay

Virginia Tech

Donald J. Orth

Virginia Tech

Charles A. Dolloff

Virginia Tech

Follow this and additional works at: https://digitalcommons.unl.edu/usdafsfacpub

Part of the Forest Sciences Commons

McManamay, Ryan A.; Orth, Donald J.; and Dolloff, Charles A., "Revisiting the homogenization of dammed rivers in the southeastern US" (2012). USDA Forest Service / UNL Faculty Publications. 160.

https://digitalcommons.unl.edu/usdafsfacpub/160

This Article is brought to you for free and open access by the U.S. Department of Agriculture: Forest Service -National Agroforestry Center at DigitalCommons@University of Nebraska - Lincoln. It has been accepted for inclusion in USDA Forest Service / UNL Faculty Publications by an authorized administrator of DigitalCommons@University of Nebraska - Lincoln. 


\title{
Revisiting the homogenization of dammed rivers in the southeastern US
}

\author{
Ryan A. McManamay a,*, Donald J. Orth ${ }^{\mathrm{a}}$, Charles A. Dolloff ${ }^{\mathrm{b}}$ \\ ${ }^{a}$ Department of Fish and Wildlife Conservation, Virginia Tech, Blacksburg, VA 24061, USA \\ ${ }^{\mathrm{b}}$ USDA Forest Service, Department of Fish and Wildlife Conservation, Virginia Tech, Blacksburg, VA 24061, USA
}

\section{A R T I C L E I N F O}

\section{Article history:}

Received 23 May 2011

Received in revised form 1 December 2011

Accepted 4 January 2012

Available online 11 January 2012

This manuscript was handled by Geoff

Syme, Editor-in-Chief, with the assistance of

John W. Nicklow, Associate Editor

\section{Keywords:}

Hydrologic alteration

Flow classification

Dam regulation

Natural flow regime

Watershed disturbance

\begin{abstract}
S U M M A R Y
For some time, ecologists have attempted to make generalizations concerning how disturbances influence natural ecosystems, especially river systems. The existing literature suggests that dams homogenize the hydrologic variability of rivers. However, this might insinuate that dams affect river systems similarly despite a large gradient in natural hydrologic character. In order to evaluate patterns in dam-regulated hydrology and associated ecological relationships, a broad framework is needed. Flow classes, or groups of streams that share similar hydrology, may provide a framework to evaluate the relative effects of dam regulation on natural flow dynamics. The purpose of this study was to use a regional flow classification as the foundation for evaluating patterns of hydrologic alteration due to dams and to determine if the response of rivers to regulation was specific to different flow classes. We used the US Geological Survey (USGS) database to access discharge information for 284 unregulated and 117 regulated gage records. For each record, we calculated 44 hydrologic statistics, including the Indicators of Hydrologic Alteration. We used a sub-regional flow classification for eight states as a way to stratify unregulated and regulated streams into comparable units. In general, our results showed that dam regulation generally had stronger effects on hydrologic indices than other disturbances when models were stratified by flow class; however, the effects of urbanization, withdrawals, and fragmentation, at times, were comparable or exceeded the effects of dam regulation. In agreement with the existing literature, maximum flows, flow variability, and rise rates were lower whereas minimum flows and reversals were higher in dam regulated streams. However, the response of monthly and seasonal flows, flow predictability, and baseflows were variable depending on flow class membership. Principal components analysis showed that regulated streams occupied a larger multivariate space than unregulated streams, which suggests that dams may not homogenize all river systems, but may move them outside the bounds of normal river function. Ultimately, our results suggest that flow classes provide a suitable framework to generalize patterns in hydrologic alterations due to dam regulation.
\end{abstract}

Published by Elsevier B.V.

\section{Introduction}

Of the many disturbances that negatively impact the integrity of aquatic ecosystems, dam regulation results in the most extensive damages (Vitousek et al., 1997). Dams reduce the hydrologic variability of river systems that is responsible for forming and maintaining the habitats to which river biota are adapted (Poff et al., 1997; Trush et al., 2000; Bunn and Arthington, 2002). A general rule of thumb is that dams tend to "homogenize" river flows across geographical scales, leading to a loss of habitat variability (Poff et al., 2007) and a homogenization of river fauna (Moyle and Mount, 2007). For example, the majority of studies show that

\footnotetext{
* Corresponding author. Present address: Oak Ridge National Laboratory, Environmental Sciences Division, Bldg. 1504, Oak Ridge, TN 37831-6351, United States. Tel.: +1540 5749154 .

E-mail addresses: mcmanamayra@ornl.gov (R.A. McManamay), dorth@vt.edu (D.J. Orth), adoll@vt.edu (C.A. Dolloff).
}

following dam regulation, minimum flow magnitudes increase whereas maximum flow magnitudes decrease (Magilligan and Nislow, 2001, 2005; Pyron and Neumann, 2008; Poff et al., 2007). Other general patterns include decreased rise and fall rates of hydrographs and increases in reversals (positive or negative changes from 1 day to the next) (Magilligan and Nislow, 2001, 2005; Pyron and Neumann, 2008). However, there are exceptions to the rule that dams influence all rivers the same. This may be especially true for rivers in the southeastern US that differ in terms of climate and geomorphology. For example, the effect of dams on monthly flows, the frequency of flows, and the timing of flows can vary due to dam type, dam operations, dam storage capacity, and are specific to different regions (Richhter et al., 1996; Magilligan and Nislow, 2005; Pyron and Neumann, 2008).

One of the obvious and more robust approaches for determining the effect of dam regulation on stream flows is by comparison of pre- and post-regulation datasets, which has been conducted extensively (Richhter et al., 1996; Magilligan and Nislow, 2001, 
2005; Poff et al., 2007; Pyron and Neumann, 2008; Gao et al., 2009). Using paired pre- and post-regulation data comparisons for individual drainages is a preferred method because it controls for differences in basin size and other confounding factors with the exception of temporal shifts in climate regimes. In addition, the criteria for selecting appropriate gages for such analyses can be quite strict (e.g. adequate pre- and post-regulation information, usually regulated by no more than one dam, and basins are not disturbed by factors other than dam regulation). Confining analyses to these criteria results in reduced sample size, reduced spatial resolution, and ultimately, a loss of information. In basins characterized by cumulative anthropogenic stressors, it may be difficult to clearly define the impacts of each stressor; thus, time-series analysis can identify break points or apparent changes in stream flow patterns attributable to different anthropogenic stressors (Vogl and Lopes, 2009). However, these specific analyses are usually limited to individual basins. Ultimately, it appears there is a need for a broader framework that provides an improved, alternative means of assessing the influence of dam regulation on stream hydrology. Such a framework could stratify basins into comparable units thereby eliminating the need, but allowing the inclusion, of preand post regulation information. However, the framework would also have to control for differences among basins, such as basin size, and account for cumulative hydrologic disturbances. Additionally, a similar framework would also be useful as structure for evaluating the effect of hydrologic alterations on aquatic biota, especially since there is limited information to develop quantitative relationships between flow alterations and ecological responses (Carlisle et al., 2010b; Poff and Zimmerman, 2010).

Geographic or geomorphic settings provide some context for evaluating hydrologic variability (Poff et al., 2006b) or patterns in hydrologic alterations (Poff et al., 2007). For example, Poff et al. (2007) used 16 regions of the US to evaluate patterns in hydrologic alterations. Although the study did show a tendency of dams to homogenize natural flow variability, the magnitude and direction in which dams influence flow dynamics were region-specific. Another approach to stratify hydrologic alteration studies is by classifying streams into groups of similar flow characteristics (Arthington et al., 2006; Poff et al., 2010) (Fig. 1). Classifications of rivers based on stream discharge data alone have been conducted at the continental scale (Poff and Ward, 1989; Poff, 1996; Kennard et al., 2010b), the regional scale (McManamay et al., 2011a), and for individual states (Kennen et al., 2007; Turton et al., 2008; Kennen et al., 2009). These flow classes can be used as ecologically-meaningful management units by which environmental flow standards are formed or as a framework for evaluating hydrologic alterations (Arthington et al., 2006; Poff et al., 2010). We hypothesize that hydrologic alterations due to dam regulation may be specific to a river's natural hydrologic predisposition (i.e. flow class membership). Flow classes represent groups of streams that share similar soils, climate, and geomorphology (McManamay et al., 2011b); thus, they should control for some of the differences among basins, thereby eliminating the necessity to use only gages with adequate pre- and post-regulation data. For example, a regulated river can be classified to a group of streams that share similar unregulated or undisturbed flow characteristics either by using pre-disturbance hydrologic information or by using landscape characteristics (Fig. 1). Flow classes then become the organizational structure by which hydrologic alterations are measured (Fig. 1).

The purpose of this study was to use a regional flow classification in the southeastern US as the foundation for evaluating patterns of hydrologic alteration due to dams. We focus our study on a region of the southeastern US because of the current and proposed increases in population and the multiple stresses on surface water demands (Sun et al., 2008). In addition, the Southeast has the highest density of dams in the US (Graf, 1999). Understanding how multiple factors affect stream flow availability, timing, duration, and frequency is critical to adapting policies to mitigate the effects of current and future impacts. Although we focus primarily on the effect of dam regulation, other disturbances, such as withdrawals and urbanization, should be considered. Lastly, it may be informative to understand how dam regulation influences the overall variability in river systems in order to adequately judge whether there may be a homogenizing effect. Our specific objectives were to (1) compare pre/post-regulation stream flow records as standard protocol to provide initial evidence for class-specific hydrologic alterations caused by dams and to warrant further investigation, (2) isolate the effects of dam regulation from other causes of hydrologic disturbance within flow classes using all stream gages, regardless of pre/post regulation hydrologic data, (3) evaluate how dam regulation influences the overall variability in river systems, and (4) generalize patterns in hydrology caused by dams across and within different flow classes.

\section{Study region}

The study region includes all or part of 8 states of the southeastern US (Georgia, Kentucky, Maryland, North Carolina, South Carolina, Tennessee, Virginia, and West Virginia). The region extends west to east from the central Appalachian Mountains to the coastal plain (Atlantic Ocean) and from north to south from the Potomac River basin in Maryland to the Savannah River basin in Georgia (Fig. 2). Basins in our study averaged $2727 \mathrm{~km}^{2}$ and ranged from 12.8 to $29,952 \mathrm{~km}^{2}$. Maximum elevations for each basin range from $15 \mathrm{~m}$ in the coastal plain to $2028 \mathrm{~m}$ in the mountainous region and average annual precipitation ranges from 93 to $207 \mathrm{~cm}$. Average slopes range from $0 \%$ to $35 \%$, with the highest in the mountainous regions. Forest coverage is the dominate land-use category in most basins averaging 67\% (10-100\%). Agriculture averages $18 \%$ (0-65\%) whereas urbanization averages $7 \%$ (0-36\%). Inceptisols soils dominate the moist climates of the mountainous areas whereas ultisols dominate the majority of the coastal plain and piedmont, with the exception of a distinct band of alfisols (clay rich) in the center of the piedmont.

\section{Methods}

\subsection{Overview}

We present a 7-step framework as a means to assess and generalize the influence of dam regulation on stream hydrology (Fig. 1). The basic principles and theoretical basis for the conceptual model were taken and modified from ideas presented by Arthington et al. (2006) and Poff et al. (2010). In general, the process includes compiling streams influenced and uninfluenced by dam regulation, stratifying basins in comparable units, accounting for cumulative hydrologic disturbances, and then isolating the effects of dam regulation. The first step includes assembling unregulated stream gages (not regulated by dams) and dam-regulated stream gages. This also includes compiling hydrologic information for regulated stream gages with periods of record proceeding dam regulation. From the group of unregulated stream gages, reference gages are selected that represent relatively undisturbed streams and then used in a flow classification (step 2). Flow classes are groups of streams that share similar natural hydrology; thus, they provide a stratified approach to evaluate hydrologic alterations or departures from natural baseline conditions. Hydrologic information or landscape characteristics are then used to develop predictive tools to assign streams to an appropriate flow class (step 3). Depending on the availability of pre-disturbance hydrologic data, unregulated streams (those not included in the classification) and regulated 


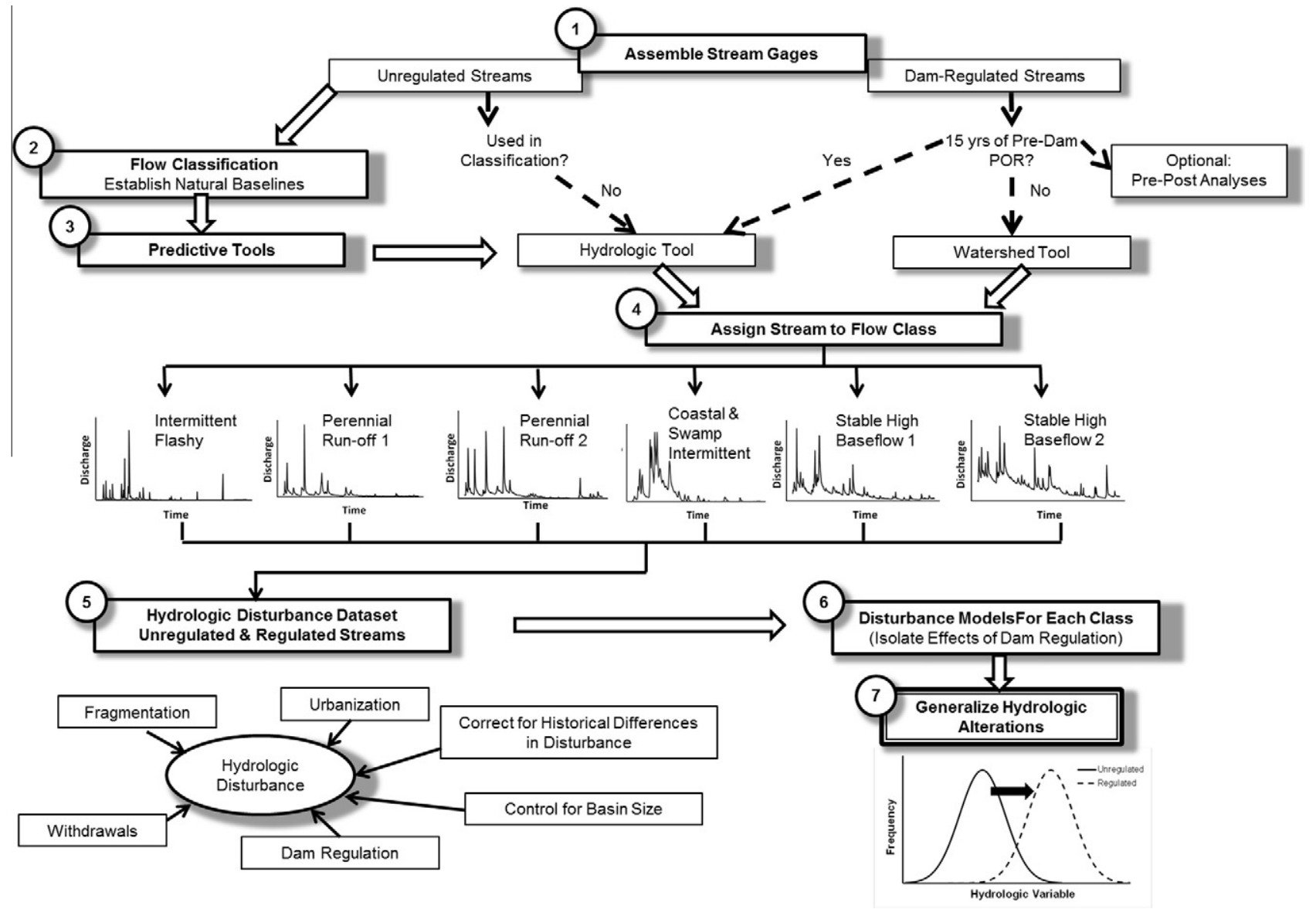

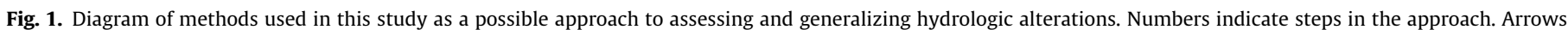

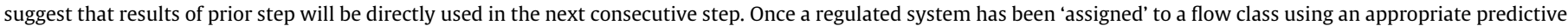

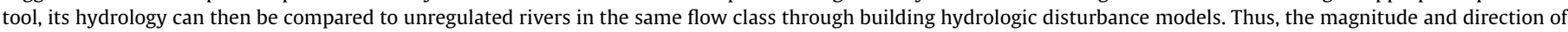

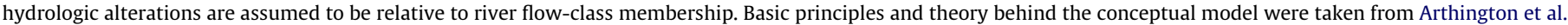
(2006) and Poff et al. (2010).

streams can be assigned to a flow class using either a hydrologic or watershed predictive tool (step 4). As an optional step, dam-regulated gages with sufficient pre- dam-disturbance hydrologic information can be used to conduct pre and post comparisons within or across different flow classes.

Although stratifying basins by flow class membership may control for natural occurring differences in soils, climate, and geomorphology, other potential hydrologic disturbances must be accounted for prior to isolating the effects of dam regulation. Thus, step 5 consists of constructing a hydrologic disturbance dataset, which includes information for 4 potential sources of hydrologic alterations: (1) watershed fragmentation, (2) urbanization, (3) withdrawals, and (4) dam regulation. Because we include predam disturbance hydrologic information and basins of various sizes, we had to account for historical differences in hydrologic disturbances and drainage area, respectively. Models for each flow class are then developed using hydrologic disturbance variables to predict values of hydrologic metrics and isolate the effects of dam regulation (step 6). Finally, step 7 attempts to generalize patterns in hydrologic alteration by comparing the hydrologic effects of dam regulation within and across flow classes using univariate or multivariate statistical procedures.

\subsection{Assembling the stream gage dataset (step 1)}

We gathered hydrologic information for unregulated and damregulated streams by accessing daily stream gage data through the
US Geological Survey (USGS) Realtime Water Data for the Nation website (http://waterdata.usgs.gov). We define unregulated stream gages as those that represent relatively undisturbed, freeflowing systems whereas regulated streams were defined as systems with flow that is partially or completely regulated by dams. To determine the unregulated or regulated status of a particular gage, we evaluated USGS annual water reports, which indicated any source of flow regulation (e.g. dams, mills, municipalities, or power plants), substantial withdrawals, and the time periods in which flow has been regulated. Preliminary criteria for selecting unregulated stream gages included no regulation by dams, no substantial withdrawals, and low urbanization. The selection of unregulated streams was further refined by using basin-specific information from the Geospatial Attributes of Gages for Evaluating Streamflow (GAGES) dataset developed by Falcone et al. (2010). More detailed information on selection criteria is provided by McManamay et al. (2011a). Gages in which dam regulation was mentioned as the primary regulation of river flows within USGS annual water reports were categorized as regulated. The majority of regulated gages were influenced by only one dam; however, we included gages influenced by multiple reservoirs in an attempt to generalize patterns in how dams affect river flow, despite differences in the amount of reservoir storage and the serial discontinuity of river systems (Ward and Stanford, 1983).

We selected unregulated and regulated stream gages with at least 15 years of total data, which should be sufficient for detecting differences in hydrologic variables summarized across entire 


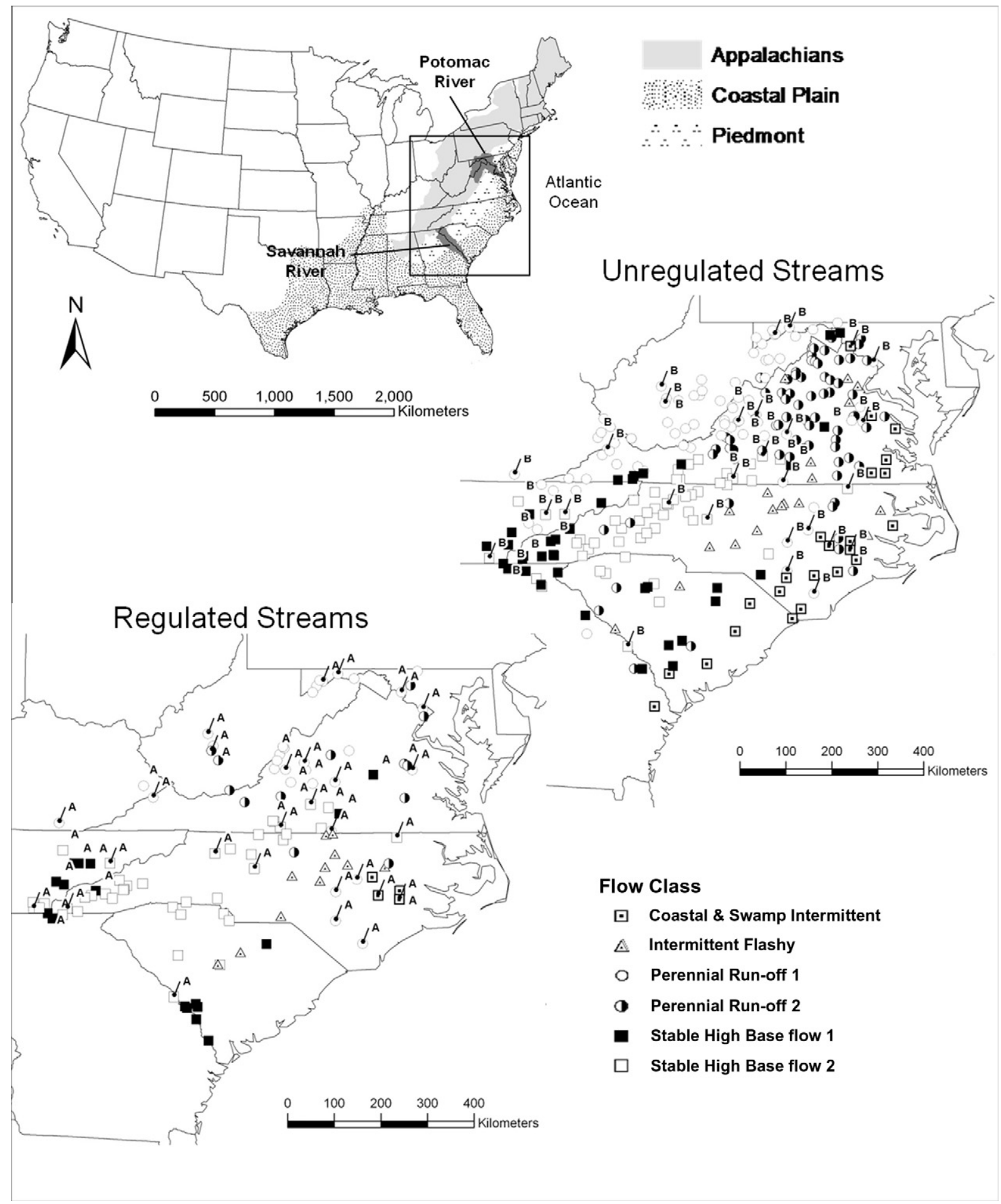

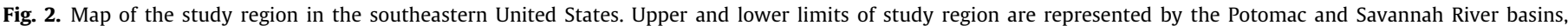

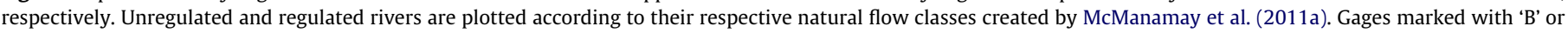

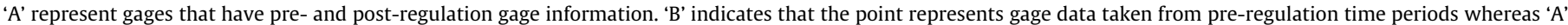
represents post-regulation gage data.

periods of record and not evaluating changes in hydrologic variables across temporal scales (Kennard et al., 2010a). We used some gage records with non-continuous or missing data as long as at least 15 total years were represented. For regulated stream gages that had at least 15 years of pre-impoundment data, we selected data from periods of time with no regulated flow to include in our analysis as unregulated status. Overall, 284 unregulated stream gage records and 117 regulated stream gage records with 15 years of record were isolated. Of the unregulated stream records, 49 consisted of streams that are currently regulated by dams but had at least 15 years of pre-dam disturbance information. Similarly, of the regulated gage records, 49 of the records consisted of post-regulation information. Gages with at least 15 years of preand post-regulation data were used in Section 3.4. 
Mean daily and annual peak flow data were downloaded from the USGS Realtime Water Data for the Nation website for 401 stream gage records (284 unregulated and 117 regulated records). Hydrologic statistics were calculated for each stream record using the Hydrologic Index Tool (HIT) software available through USGS (Henriksen et al., 2006). Daily and peak flow gage data for the entire period of record were imported into HIT, which calculates the 171 hydrologic indices reported in Olden and Poff (2003). The indices are grouped into five categories of flow: magnitude $(n=94)$, frequency $(n=14)$, duration $(n=44)$, timing $(n=10)$, and rate of change $(n=9)$ with each category having low, average, and high flow subcategories (Richhter et al., 1996; Olden and Poff, 2003). Because the 171 hydrologic variables are correlated and highly redundant (Olden and Poff, 2003), we originally reduced the dataset to 40 variables (Table 1 ), which included the 33 Indicators of Hydrologic Alteration (IHA) (Richhter et al., 1996), three Environmental Flow Component (EFC) indices (Mathews and Richter, 2007), and 4 of the variables found in Poff (1996). Olden and Poff (2003) showed that the IHA variables and EFC variables explained the majority of variation in all 171 published hydrologic indices. Because several of the IHA variables were not calculated for some streams and would limit our multivariate analyses, we included four additional variables from Poff (1996) bringing the total number of hydrologic variables to 44 (Table 1 ). All magnitude variables and any variables related to magnitude were divided by the median daily flow for each stream to standardize for differences in river size, which is a commonly used approach when evaluating hydrologic variability over spatial scales (Poff and Ward, 1989; Poff et al., 2006; Kennard et al., 2010b). We presume that standardization by median flow is a preferred method over standardization by drainage area since hydrologic variables share non-linear relationships with drainage area (Leopold, 1994).

\subsection{Flow classification, predictive tools, and assigning gages to flow classes (steps 2-4)}

Flow classifications have been proposed as a robust framework for generalizing hydrologic alterations across regions by stratifying basins into comparable units (step 2, Fig. 1) (Arthington et al., 2006; Poff et al., 2010). For our region of interest, McManamay et al. (2011a) classified 292 streams into six distinct flow classes representing differences in the magnitude, frequency, duration and rate of change in flow regimes. These classes provide the hydrologic baseline from which departures in flow due to disturbance can be measured.

Predictive tools, or classification models, are commonly developed to accompany hydrologic classifications as mechanisms used to assign streams to appropriate classes (step 3, Fig. 1) (Kennen et al., 2007; Kennard et al., 2010b; Olden et al., 2011). These predictive tools can be used to classify gaged streams not used in the original classification or ungaged streams with sufficient climate, soils, and toprographical information. In association with the flow classification, McManamay et al. (2011a) developed a hydrologic classification tool, which consisted of five hydrologic variables that could classify a stream gage to 1 of 6 flow classes with 85\% accuracy. In addition, McManamay et al. (2011b) built a watershed classification tool that accurately classified $74 \%$ of streams to their appropriate flow class using primarily soil and climate variables. The watershed tool was built using the GAGES dataset (Falcone et al., 2010), which includes soils, topographic, and climate information summarized across the contributing watershed upstream of each gage. The GAGES dataset includes information for 6785 USGS gages with at least 20 years of data, which included the regulated stream gages used in our study.

The next critical step in forming generalizations of dams affect flow dynamics is by assigning streams to a particular class (step 4, Fig. 1) (Arthington et al., 2006; Poff et al., 2010). The majority of unregulated gage records in our dataset $(n=273$ of 284) and some of the regulated gages with pre-regulated data $(n=38$ of 117$)$ were used in the flow classification and thus, were already assigned to 1 of 6 flow classes. For the remainder of unregulated $(n=11)$ and regulated $(n=78)$ gage records, we used one of the two predictive tools to assign gages to appropriate flow classes depending on the availability of hydrologic data. For regulated streams with at least 15 years of pre-regulation hydrologic information, we used the hydrologic classification tool to assign those gages to a flow class. Because the majority of regulated gages had inadequate pre-regulation hydrologic data, we used the watershed classification tool created by McManamay et al. (2011b) to assign gages to 1 of 6 flow classes. One limitation of this approach is that some gages may be misclassified. Because flow classes represent clouds or aggregations in multivariate space, some streams within a particular class may be located near border of an adjoining cloud and thus, more prone to misclassification, which is a typical drawback from hard, centroid-based clustering (Jain, 2010). However, misclassification rates are typically low and result in gages being assigned to flow classes that share similar hydrology (McManamay et al., 2011b). For example, McManamay et al. (2011b) found that stable high baseflow 1 (SBF1) streams share similar geographical extent and similar baseflow characteristics with stable high baseflow 2 streams (SBF2). If SBF1 streams are classified inaccurately using watershed classification trees, they are typically misclassified as SBF2 streams. Thus, we hypothesize that classes that share similar hydrology might respond similarly to dam regulation.

Table 1

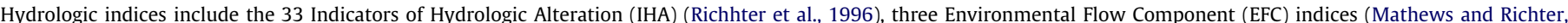

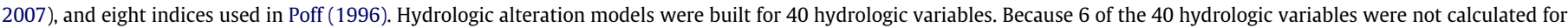
some streams, additional variables were included in the principal components analysis (PCA)

\begin{tabular}{|c|c|c|c|}
\hline Flow variability ${ }^{\mathrm{a}}$ & November flow & 7-Day minimum & Flood duration $^{\mathrm{d}}$ \\
\hline January flow & December flow & 30-Day minimum & Flow predictability ${ }^{\mathrm{a}}$ \\
\hline February flow & Minimum July flow ${ }^{\mathrm{b}, \mathrm{c}}$ & 90-Day minimum & Seasonal flood predictability ${ }^{\mathrm{a}}$ \\
\hline March flow & Base flow index & Low flow duration & Seasonal predictability (low flow) $)^{\mathrm{a}, \mathrm{d}}$ \\
\hline April flow & Low pulse count & No. of zero flow days ${ }^{\mathrm{C}}$ & Seasonal predictability (non-low flow) ${ }^{\mathrm{a}, \mathrm{d}}$ \\
\hline May flow & Low pulse variability ${ }^{\mathrm{b}, \mathrm{c}}$ & 1-Day maximum & Seasonal predictability (non-flooding) ${ }^{\mathrm{a}, \mathrm{d}}$ \\
\hline June flow & High pulse count & 3-Day maximum & Date of annual minimum \\
\hline July flow & High pulse variability ${ }^{\mathrm{b}, \mathrm{c}}$ & 7-Day maximum & Date of annual maximum \\
\hline August flow & Flood frequency ${ }^{\mathrm{a}, \mathrm{c}}$ & 30-Day maximum & Rise rate \\
\hline September flow & 1-Day minimum & 90-Day maximum & Fall rate \\
\hline October flow & 3-Day minimum ${ }^{c}$ & Flood interval $^{\mathrm{a}}$ & Reversals \\
\hline
\end{tabular}

a Poff (1996).

b EFC (Mathews and Richter, 2007).

c Used in hydrologic alteration model but not PCA.

${ }^{\mathrm{d}}$ Used in PCA but not hydrologic alteration model. 


\subsection{Pre- and post-regulation analysis (optional step)}

Because pre/post analyses have dominated the literature, we wanted to use this analysis to provide some justification that flow classes can be used as a basis for evaluating hydrologic alterations. After all stream gages were classified to an appropriate class, we calculated percent changes in 10 ecologically-relevant hydrologic variables following dam regulation for the 49 gages with 15 years each of pre- and post-regulation data. We chose the 10 hydrologic variables because they dominate studies which evaluated the hydrologic effects of dams using pre-post regulation information (Richhter et al., 1996; Magilligan and Nislow, 2001, 2005; Poff et al., 2007; Pyron and Neumann, 2008). We used unstandardized values for hydrologic variables rather than those standardized by the median daily flow for the before/after analysis because comparisons were from the same basin. We sorted each pre-post analysis by flow class and evaluated percent changes among different flow classes using box plots.

\subsection{Hydrologic disturbance dataset (step 5)}

Determining the influence of dams on flow dynamics by using only gages with adequate pre- and post-regulation data may limit sample sizes and exclude important information in analyses. For example, only 49 of the 117 regulated gages in our study region had adequate pre-regulation data. Therefore, to increase sample size, we evaluated gross differences in hydrologic variables between regulated and unregulated streams, regardless of the availability of pre-regulation information. One limitation of this approach is that gross comparisons may not account for differences in watershed characteristics and other disturbance factors besides dam regulation.

In order to account for other hydrologic disturbances that may confound our analyses, we assembled a hydrologic disturbance dataset using the GAGES database, which includes 27 dam regulation variables, 11 hydrologic modification variables (e.g. withdrawals), and a large suite of land-use metrics for 6785 stream gages in the US (Falcone et al., 2010). Each variable represents a summary for each gage's entire basin and not just values at each gage location. One challenge that arose with our dataset was that the values for the hydrologic disturbance variables for each gage were based on current conditions. Thus, disturbance values for gages with both pre- and post-regulation records were similar. For example, dam disturbance variables, such as total dam storage, were based on 2006 National Dam Inventory Data (USACE, 2011) whereas landuse variables, such as\% urbanization and \% fragmentation in the watershed, were based using the 2001 National Land-Cover Dataset (NLCD). Freshwater withdrawal estimates came from 1995 to 2000 county-level estimates from USGS datasets. Thus, to use hydrologic data from the pre-regulation time periods in our dataset, we had to correct for recent changes in water use, dam regulation, and land use. The GAGES dataset included changes in total dam storage and dam density for each gage in every decade since 1940 , which allowed for easily correcting for differences in total storage in each basin. If the dam regulation time period was prior to 1930 , then we assumed a value of 0 for both dam storage and dam density.

Historical values for withdrawals and land use were not as readily available as dam regulation information. We used the 2005 USGS national water report (Kenny et al., 2009) to evaluate changes in withdrawals over time. Trends in water withdrawals were available for each major water consumption category across the US since 1950 (public supply, domestic, irrigation, livestock, industrial, and thermoelectric) (Supplementary material 1). Most categories showed general increases in water use since 1950 except for industrial uses (Supplementary material 1). We developed linear regressions or second-order polynomial regressions on percent changes in withdrawals according to year for each category. The proportion of water use in each category was also available for each state (Supplementary material 2). Because water use in different consumption categories varies substantially from state to state (Kenny et al., 2009), the percent changes in withdrawals were weighted by water use in each category for each state depending on the location of each gage. We then applied regressions for each gage based on the year since dam regulation to correct withdrawal estimates. Thermoelectric withdrawals dominated water usage trends for most states and across the US; however, based on USGS annual water reports, thermoelectric usage is patchy and does not occur in every basin. Since accounting for thermoelectric usage in each basin could heavily influence our historical withdrawal estimates, we only included trends in thermoelectric usage for gages in which the USGS water reports mentioned some flow regulation due to power plants within the basin.

Historical trends in land use since 1950 were available for the southeastern US according to seven different level-3 ecoregions (Brown et al., 2005) (Supplementary material 3). We ran regressions for percent changes in each land-use category (\% urban and $\%$ agriculture) for each ecoregion. We corrected for changes in \% urban and \% agriculture land cover types using the year since dam regulation depending on the ecoregion in which each gage was located. Watershed fragmentation is an index based upon the percentage of undeveloped land (non-urban and non-agricultural land - higher index values indicate more fragmentation (Falcone et al., 2010)). Because \% agriculture showed relatively little change (0-21\% decrease) compared to urbanization (33-103\% increase), we used changes in \% urban land cover to account for any changes in fragmentation.

One of the limitations in our analysis for correcting withdrawal and land-use estimates is that we assume patterns across the US and across entire ecoregions are representative of patterns within each basin. Also, our corrected withdrawal and land cover estimates were highly dependent upon current estimates (corrected using \% change); thus, if withdrawal and urbanization is currently high within a particular basin, pre-regulation estimates should reflect current high conditions. However, we do not expect that slight inaccuracies in assessing historical estimates would overwhelm our analyses since there are only 49 pre-regulation gages out of the 284 unregulated gages. Lastly, flow classes represent differences in hydrology that vary according to watershed, climate, and geography. Thus analyzing patterns of dam regulation within flow classes should control for some factors that may confound our analyses.

Regulated and unregulated rivers may show a large gradient of hydrologic alteration. Falcone et al. (2010) used a subset of the disturbance variables to calculate a hydrologic disturbance index (HDI) for all streams in the database. The HDI can be used as a composite score to provide some assessment of cumulative hydrologic disturbances within each basin and can be used to examine the various contributors to hydrologic alteration. After we assembled the hydrologic disturbance variables, we developed a new HDI for the study region. We chose a subset of the hydrologic disturbance variables that were pertinent to our analysis (freshwater withdrawals, total dam storage, major dam density, \% urban landcover, and fragmentation). Similar to Falcone et al. (2010), we calculated thresholds for each disturbance variable based on percentiles (10\% increments). We then assigned scores of 1-10 for each variable and the sum of the scores was used to calculate a HDI for each stream. We imported all gages, their GPS locations, and their HDI values into ARC map 9.2. We used natural breaks (Jenks, 1967) to categorize the HDI into low, low to moderate, moderate, moderate to high, and high categories. We then plotted unregulated and regulated streams on maps to visualize overall 
hydrologic disturbance in the region. Since HDI values follow a Poisson distribution, we compared the hydrologic disturbance index values in regulated and unregulated streams for all streams using a Mann-Whitney Test.

\subsection{Hydrologic disturbance models (step 6)}

We hypothesized that flow classes would provide a suitable stratification for generalizing the effects of dam regulation on hydrology because they may account for natural variation in flow. However, other natural factors may be important. For example, differences in drainage area can substantially influence flow dynamics (Poff et al., 2006a). Although hydrologic variables were standardized by the median daily flow, many were still related to drainage area. To control for differences in basin size, we ran regressions for each hydrologic variable versus drainage area for only unregulated streams and then calculated residuals for both regulated and unregulated streams. We preferred this method over dividing by drainage area because it allowed us to develop natural relationships for unregulated streams that could be extrapolated to regulated streams. Using only unregulated streams to form regressions ensures that relationships between drainage area and hydrologic variables are natural and not biased due to regulated rivers with larger basins. We ran separate regressions for all streams and for each class. Typically, hydrologic variables typically follow lognormal distributions (Vogel and Wilson, 1996); thus, all hydrologic variables and drainage area were $\log (x+1)$ transformed prior to any analysis.

After we calculated residuals, we plotted the mean residual value for each hydrologic response variable according to flow class and according to regulation type (unregulated or regulated) for all 401 streams. We wanted to compare the range of values in hydrologic variables represented by flow classes relative to regulation type in order to further justify the inclusion of flow classes in our analyses. Because our analyses had to control for the influence of other hydrologic disturbances in addition to the effects of class membership, we conducted a Multivariate Analysis of Covariance (MANCOVA) to test for the effect of dam regulation (regulated versus unregulated) and flow classes $(n=6)$ on 40 hydrologic variables for all 401 streams while controlling for the effects of urbanization, withdrawals, and fragmentation covariates. MANOVA and MANCOVA procedures are robust against violations of normality and do not assume sphericity, or equal variances among dependent variables (Zar, 1999). Although hydrologic variables in unregulated streams tend to be correlated (Olden and Poff, 2003), hydrologic variables may respond differently to dam regulation and should be tested individually; thus, we used an identity matrix which calculates the response of each variable separately (SAS, 2008). For the whole model and flow class, we used Wilks' lambda as an indication of the amount of variation unaccounted for by each factor (Wilks, 1932) and we present Pillai's trace statistic as a comparison since it tends to be more conservative (Pillai, 1955; Zar, 1999). Wilks' Lambda and Pillai's trace statistics are calculated from matrices of sum-of-squares and interaction products; thus, their values are transformed into approximate $F$ values and $p$ values can be calculated. Exact $F$ values are calculated for factors composed of only 1 effect (i.e. single sum-of-squares values) and not interaction effects (SAS, 2008).

Although MANCOVAs can be informative in determining the relative importance of various explanatory variables, they do not yield sufficient results, such as the magnitude and direction in the response of each variable. For example, MANCOVAs provide parameter estimates for each variable; however, parameter estimates themselves are not necessarily comparable among different explanatory variables nor do they indicate significance. In addition, we wanted to evaluate the response of hydrologic variables to dam regulation within each flow class separately; however, the identity matrix used for the MANCOVA was too complex given the sample size in some of our classes. Thus, for all streams and for each flow class, we built general linear models using dam regulation (regulated or unregulated) along with other hydrologic disturbance variables (withdrawal estimates, fragmentation index, and \% urban landcover) to predict responses in the residuals of 40 hydrologic variables. We then compared $t$-statistics calculated for the dam regulation parameter in each of the linear models constructed for all 40 hydrologic variables in all streams and in each flow class. We used $t$-statistics rather than actual parameter estimates because their single value represents the directionality of each parameter (+ or - ) with respect to the standard error as well as the significance level. In addition, because t-statistics are less variable and show directionality compared to $F$ statistics (provided in ANCOVA tests), they are easier to graph among many different hydrologic variables. Although there may be associated inflation in the Type I error due to constructing individual models for each hydrologic variable, our analysis should provide some ability to evaluate general trends in the responses of hydrologic variables among flow classes.

It also may be informative to compare the effects of dam regulation to that of other hydrologic disturbances. We compared the mean $t$-statistic for each of the hydrologic disturbance parameters (dam regulation, withdrawal, fragmentation, urbanization) for nine hydrologic variables using the six flow classes as replicates $(n=6)$. We arbitrarily chose a subset of nine variables that were easily interpretable and had high $R^{2}$ values in hydrologic disturbance models to provide an example of the potentially conflicting effects of different disturbances on hydrologic variables. Because we had used exclusive classes (regulated or unregulated) to represent dam regulation, we questioned whether a more continuous variable, such as total dam storage would be more powerful in a linear model. Furthermore, classifying streams as regulated or unregulated may be easier than calculating total dam storage. Thus, we re-ran the models for the nine hydrologic variables using total dam storage (storage/drainage area) rather than the regulatedunregulated classes and compared their $t$-statistics. Hydrologic disturbance predictors were $\log (x+1)$ or arcsin square root transformed where appropriate.

\subsection{Overall variation in flow dynamics of regulated and unregulated streams}

Because unregulated streams cluster together (i.e. form classes) and share correlative structure, it may be informative to explore the influence of hydrologic alterations on natural flow dynamics in multivariate space. We conducted principal component analyses (PCA) on correlations for regulated and unregulated rivers for all streams and within flow classes to examine how dam regulation may influence the overall variation of the hydrologic variables using JMP 8.0 software (SAS, 2008). We conducted a PCA on 38 variables rather than the 40 variables used in the hydrologic disturbance models because of missing values and the inclusion of other variables (Table 1). We ran PCAs on correlations since PCAs on covariance resulted in individual variables having the highest loadings on multiple components. We did not control for differences in land use, withdrawals, or drainage area because we wanted to see the overall existing correlation of streams in multivariate space. Variables were standardized by subtracting each value by the sample mean and then dividing that value by the sample standard deviation prior to analysis.

We used the broken-stick method to determine how many principal components to retain because it is simple to calculate, accurately assesses dimensionality, and does not overestimate the number of interpretable components compared to other methods 
(Jackson, 1993). The broken-stick rule involves comparing eigenvalues calculated from random data to eigenvalues from the actual data. The number of interpretable components is found where the eignevalues from random data exceed those of the actual data (Jackson, 1993). We manually calculated eigenvalues for randomdata according to Jackson (1993) to find the number of interpretable components. For each component, we sorted variables by loading factor in increasing order and then plotted the distribution to select outliers or breaks in order to interpret components. Because hydrologic variables can be highly correlated within unregulated streams (Olden and Poff, 2003), isolating a few variables with the highest loadings on each principle component may be difficult. Most components had obvious outliers with strong negative or positive loadings. However, in components without obvious outliers, we manually chose up to a maximum of five variables on either side of the distribution to interpret components. We plotted regulated and unregulated streams on 3-dimensional scatter-plots using the first three components to visually evaluate the divergence of regulated and unregulated streams within Sigma Plot 9.0. We spun the principal components in order to display the most divergence between regulated and unregulated streams.

\section{Results}

Overall, our dataset contained 284 unregulated and 117 regulated stream records. Of the 284 unregulated stream records, 273 were used in the original classification by McManamay et al. (2011a), which included 38 regulated records with at least 15 years of pre-regulation hydrologic information (Supplementary material 4). Similarly, 38 of the 117 regulated stream records with at least 15 -years of post-regulation information had also been assigned to an appropriate class (Supplementary material 4). We found an additional 11 currently-regulated streams with sufficient preand post-regulation data. Thus, 11 unregulated and 11 regulated stream records were assigned to appropriate classes using the hydrologic classification tree (Supplementary material 4). The remaining 68 regulated stream records were assigned to appropriate classes using the watershed classification tree (Supplementary material 4). The unregulated streams were dominated by perennial run-off 1 and 2 streams (PR1 and PR2), followed by SBF1 and SBF2 streams, and a fewer number of coastal swamp and intermittent streams (CSI) and intermittent flashy streams (IF) (Supplementary material 4). Regulated streams, as a whole, had fairly broad representation across the region of interest (Fig. 2) and followed a similar distribution to that of unregulated streams (Supplementary material 4). However, SBF2 streams dominated the number of regulated streams followed by PR1 streams. In general, regulated streams were adequately represented across various classes, and yielded a similar geographical distribution as the unregulated streams (Fig. 2). In contrast, gages with adequate pre- and postregulation information composed less than 50\% $(n=49)$ of the 117 regulated gages in our study, were not adequately represented across all 6 flow classes, and were generally clustered to individual drainage basins (Fig. 2).

\subsection{Pre- and post-regulation analysis}

The response of hydrologic variables to regulation was substantially different among the flow classes represented (Fig. 3). For example, for the base flow index and the annual minimum, PR1 and CSI streams showed positive changes whereas the SBF streams showed negative changes. Similarly, PR1 and CSI streams showed positive changes in flow predictability whereas SBF streams showed negative changes. In addition, some variables, such as the flood interval, showed highly variable responses, whereas other variables, such as the rise rate, showed similar responses across all flow classes. The responses to regulation were also variable within some of the flow classes. For example, streams within the stable high baseflow class showed variable responses in the low flow pulse count, high flow pulse count, and the flood interval in response to regulation.

\subsection{Hydrologic disturbance dataset}

We plotted regulated and unregulated streams according to their HDI values to evaluate the degree of hydrologic alteration between unregulated and regulated streams and within regulated streams (Fig. 4). Mean HDI values were significantly higher in regulated streams $(x=13.9)$ compared to unregulated streams $(x=20)$ (Mann-Whitney Test, $\chi^{2}=93.73, p<0.0001$ ). The standard deviation of HDIs in unregulated streams was higher than that of regulated streams $(\mathrm{SD}=5.13$ and 4.79 , respectively). Although unregulated streams were dominated by HDIs in the low and low-to-moderate categories, several unregulated streams had HDIs in the moderate-to-high and a few in the high categories. Likewise, although regulated streams were dominated by moderate and high HDIs, many regulated streams had low and low-to-moderate HDIs.

\subsection{Hydrologic disturbance models}

Prior to conducting the MANCOVA and developing disturbance models, we ran regressions for each hydrologic variable versus drainage area for only unregulated streams to control for differences in basin size in regulated and unregulated streams. The mean drainage area for regulated rivers was $4660 \mathrm{~km}^{2}(\mathrm{SD}=6257$ ), which was quite larger than the mean drainage area of unregulated rivers $\left(\bar{x}=1963 \mathrm{~km}^{2}, \mathrm{SD}=4157\right)$. Drainage area explained $0-73 \%$ of the variation in hydrologic indices for unregulated streams depending on flow class and the individual hydrologic index ( $r^{2}$ adj.) (Appendix A). We also compared the response of the residuals of each hydrologic variable to flow class membership relative to regulated and unregulated class membership. Flow classes captured a larger range in the average of hydrologic responses compared to the gross unregulated vs. regulated classification (Fig. 5). Thus, we accounted for flow class membership because we hypothesized that they provided the foundation for measuring hydrologic disturbances. Results of the MANCOVA showed that the whole model and the effects of all factors (flow class, dam regulation, urbanization, withdrawal, and fragmentation) were significant in explaining the responses of the 40 hydrologic variables (Table 2 ). Although all factors had significant effects, dam regulation had the largest $F$ statistic and thus, the largest relative effect compared to the other factors.

We evaluated the effect of dam regulation along with three other hydrologic disturbance variables for 40 hydrologic indices using general linear models for all streams and for individual flow classes after controlling for drainage area (Appendix B). After controlling for drainage area, disturbance models explained from $0 \%$ to $69 \%$ of the variation in hydrologic variables depending on the flow class and depending on the hydrologic response variable (Table 5). For all streams ( $n=401)$, 39 of the 40 hydrologic disturbance models were significant; however, on average, the models for all streams explained only $10 \%$ of the variation with a maximum of $26 \%\left(R^{2}\right.$ adj.) (Table 5). Dam regulation explained the majority of variation in models for all streams in 36\% (14/39) of cases. For models within the 6 flow classes, only 37 of the 240 were statistically significant and explained a maximum of $69 \%$ of the variation (Table 5). Of the statistically significant models within flow classes, dam regulation explained the majority of variation in 65\% (24) of the cases (Table 5). However, withdrawal, fragmentation, and urbanization explained a substantial amount of the overall variation in many models, which at times, was higher than the variation explained by dam regulation. 

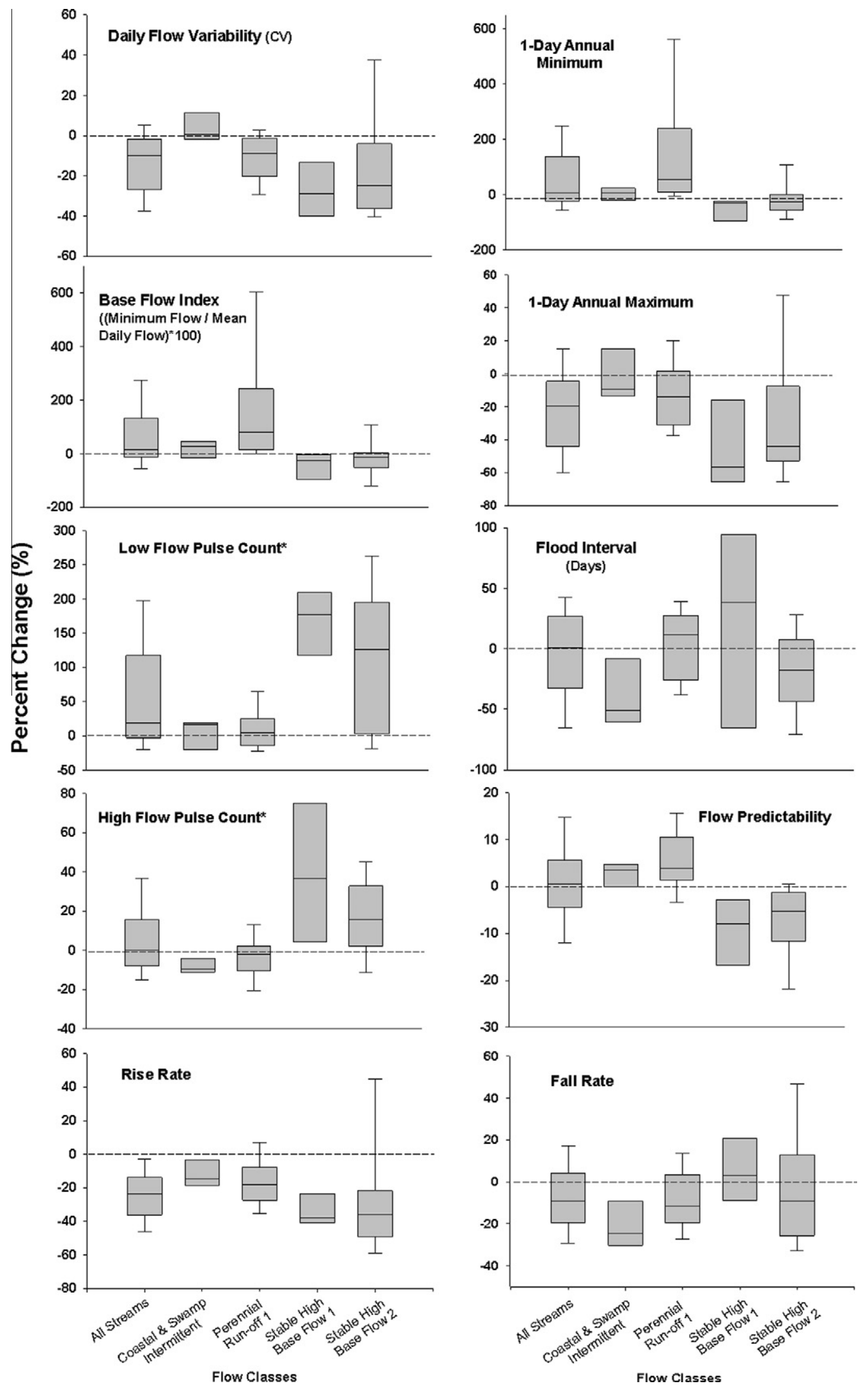

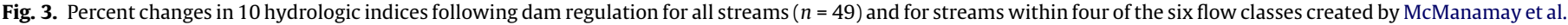

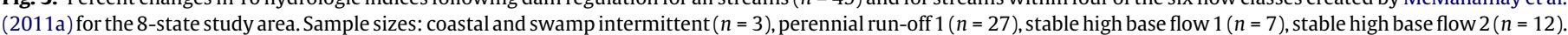

The direction and magnitude of the $t$-statistic values for dam regulation varied substantially among flow classes for some hydrologic indices whereas other hydrologic indices showed consistent patterns across all flow classes (Figs. 6 and 7). For example, IF, PR1, and PR2 streams showed positive changes in the base flow index with regulation whereas the SBF1 and SBF2 streams showed 


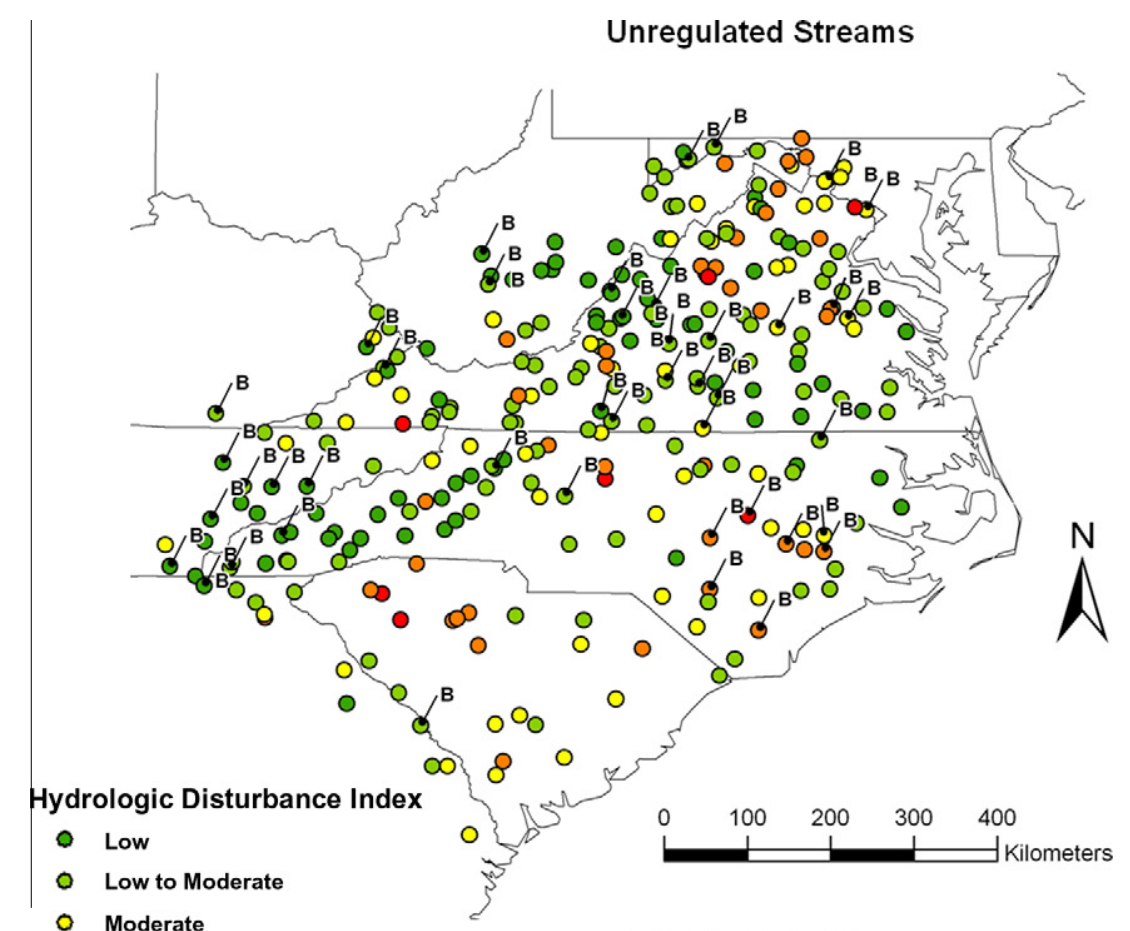

- Moderate

- Moderate to Hlgh

Regulated Streams

- High

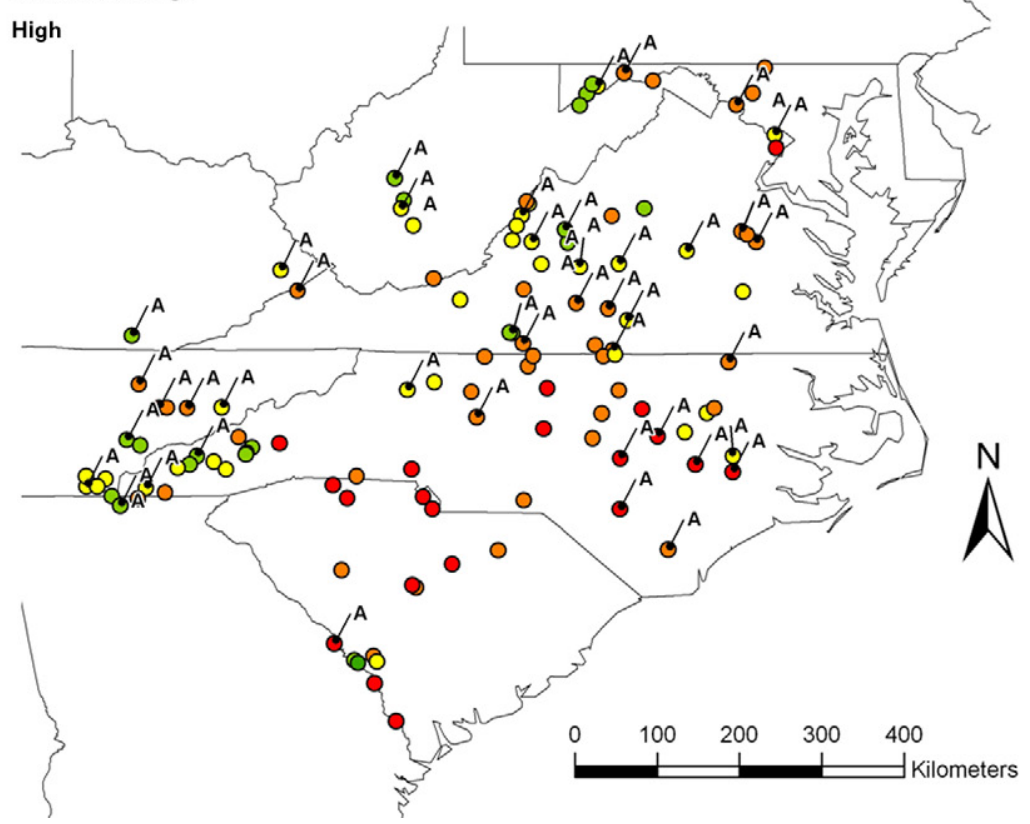

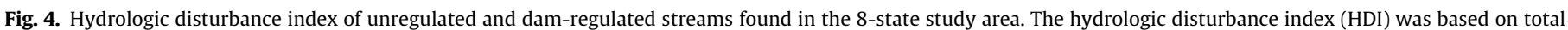

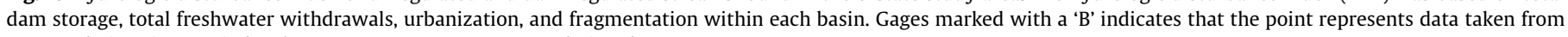
pre-regulation time periods whereas ' $A$ ' represents post-regulation data.

negative changes (Figs. 6 and 7). In addition, the magnitude and direction of changes in various monthly flows and minimum/maximum flows were class-specific. In contrast, flow variability, rise rate, and the number of reversals all showed consistent negative changes across all flow classes.

Since we included other hydrologic disturbances in models, we were able to compare the relative influence of dam regulation in comparison to urbanization, fragmentation, and withdrawals. Dam regulation had the largest and most consistent $t$-statistics relative to the other disturbance variables across flow classes (Fig. 8). However, urbanization showed large $t$-statistic values that generally had similar directionality to dam regulation. In contrast, withdrawals and fragmentation had smaller mean $t$-statistics, but generally showed opposite directionality relative to dam regulation and urbanization. Comparisons of the directionality and magnitude of the $t$-statistics for dam storage (continuous variable) and dam regulation (categorical variable) parameter estimates were very similar (Fig. 8).

\subsection{Overall variation in flow dynamics of regulated and unregulated streams}

We retained the first four principal components for all stream classes because the eigenvalues from random data exceeded the 

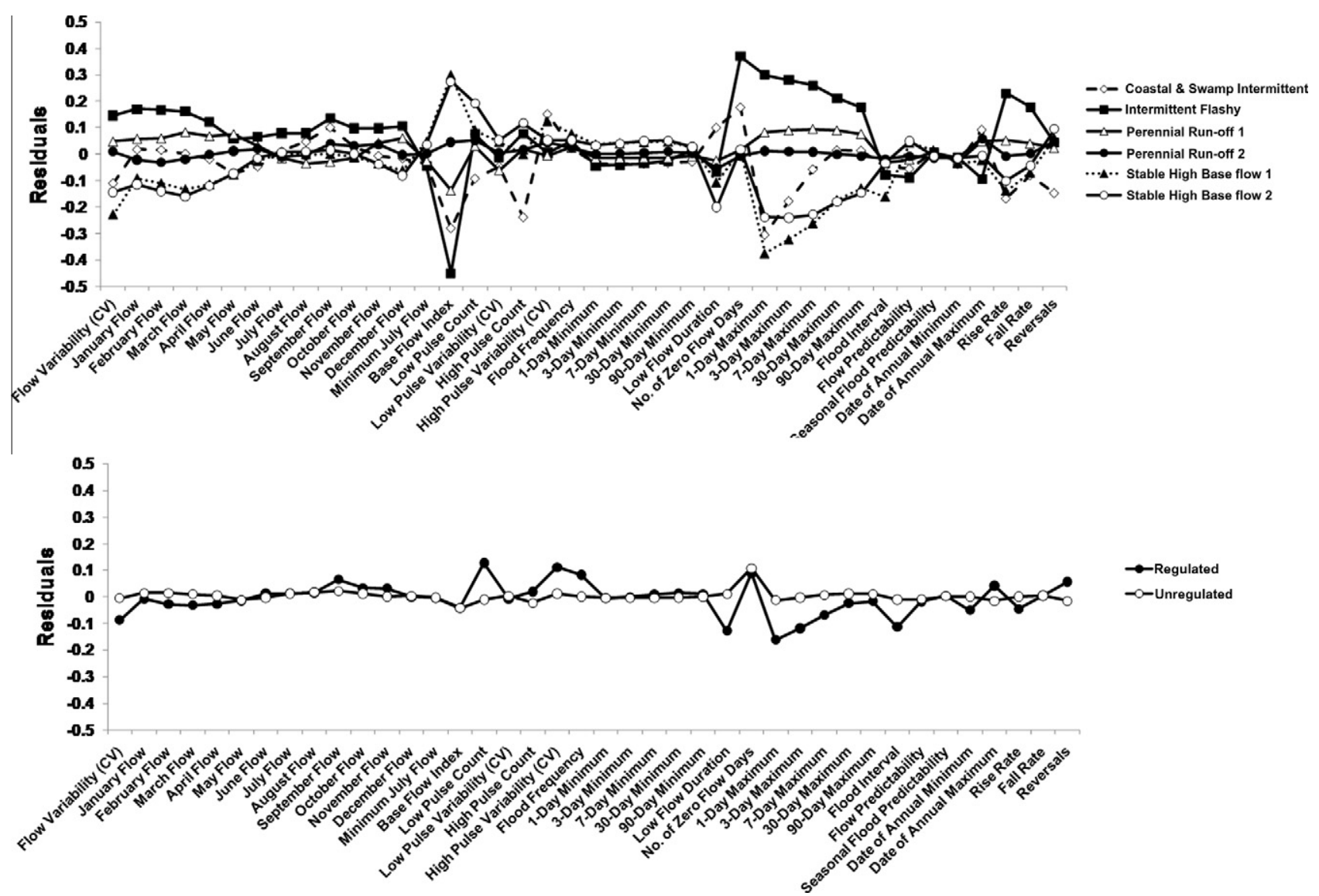

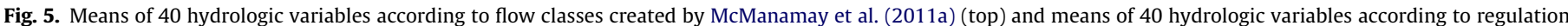

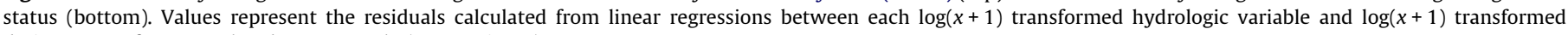
drainage area for unregulated streams only (see Section 3 ).

Table 2

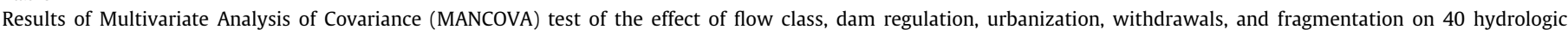

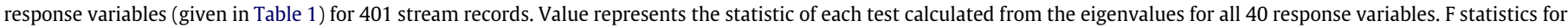

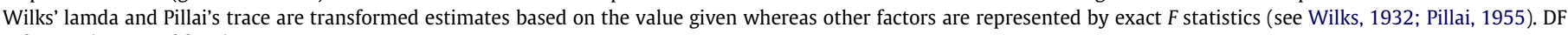
refers to degrees of freedom.

\begin{tabular}{|c|c|c|c|c|c|}
\hline Test & Value & $F$ statistic & Numerator DF & Denominator DF & Prob $>F$ \\
\hline \multicolumn{6}{|l|}{ Whole model } \\
\hline Wilks' lambda & 0.00 & 9.05 & 360 & 3039 & $<.0001$ \\
\hline Pillai's trace & 4.11 & 7.37 & 360 & 3159 & $<.0001$ \\
\hline \multicolumn{6}{|l|}{ Intercept } \\
\hline Exact $F$ & 0.50 & 4.30 & 40 & 343 & $<.0001$ \\
\hline \multicolumn{6}{|l|}{ Class $(n=6)$} \\
\hline Wilks' lambda & 0.02 & 10.86 & 200 & 1710 & $<.0001$ \\
\hline Pillai's trace & 2.58 & 9.24 & 200 & 1735 & $<.0001$ \\
\hline \multicolumn{6}{|c|}{ Dam regulation ( $R$ vs. UR) } \\
\hline Exact $F$ & 1.41 & 12.13 & 40 & 343 & $<.0001$ \\
\hline \multicolumn{6}{|l|}{ Urbanization } \\
\hline Exact $F$ & 0.46 & 3.98 & 40 & 343 & $<.0001$ \\
\hline \multicolumn{6}{|c|}{ Freshwater withdrawal } \\
\hline Exact $F$ & 0.33 & 2.84 & 40 & 343 & $<.0001$ \\
\hline \multicolumn{6}{|l|}{ Fragmentation } \\
\hline Exact $F$ & 0.47 & 4.04 & 40 & 343 & $<.0001$ \\
\hline
\end{tabular}

eigenvalues from the actual data at four components (Fig. 9). We plotted the first three principal components for all streams and for each individual flow class. Unregulated streams showed very close clustering where classes filled a small multivariate niche (Fig. 10). Regulated streams, however, showed more of a random structure where streams from some flow classes had migrated into the multivariate space of others. For all streams in our dataset, four of the five key aspects of the natural flow regime (magnitude, timing, frequency, and duration) were represented by hydrologic indices with high loadings in the first 3 PCs (Fig. 10). Hydrologic indices with high loadings were substantially different for different flow classes. The grouping of regulated and unregulated streams also differed depending on class. In some classes, the influence of regulation was observed along one component whereas in others, it 

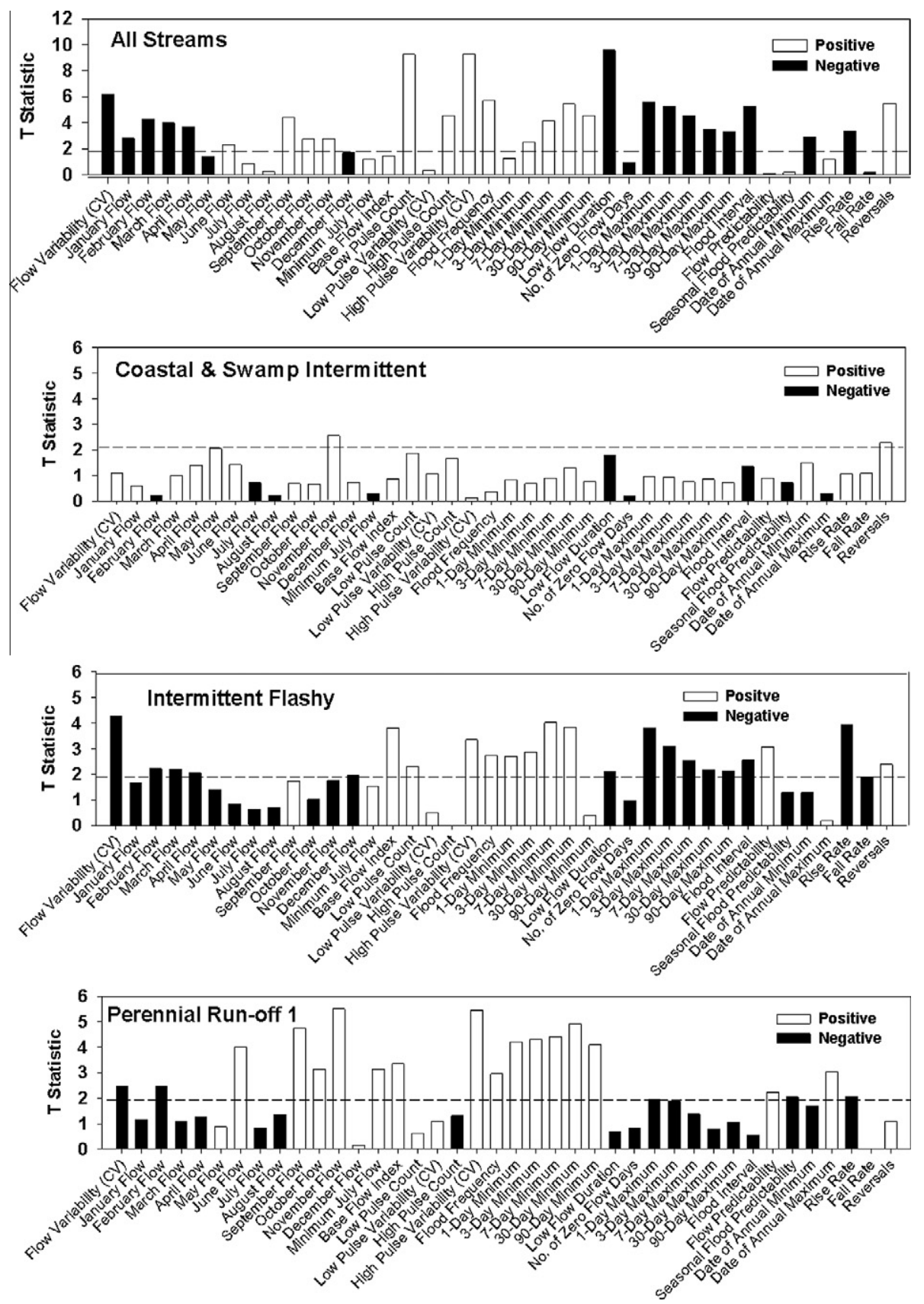

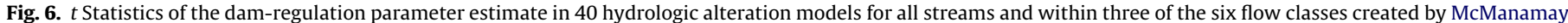

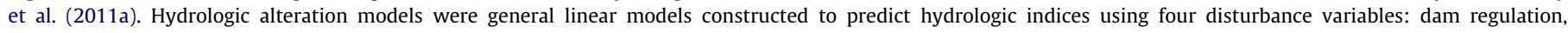

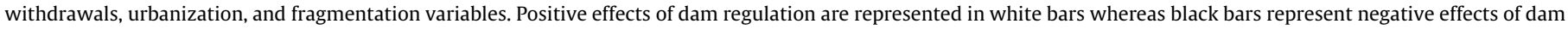
regulation. Dashed line indicates the significance of the $t$-statistic for each hydrologic index.

was observed along all three components (Fig. 11). For example, unregulated and regulated SBF2 streams seemed to show major divergence on the basis of seasonal flow predictability whereas SBF1 streams showed major divergence on the basis of the number of reversals, flow frequency, flow magnitude, and flow variability. The PCA for individual classes also isolated obvious outlier streams that show the most divergence or disturbance.

\section{Discussion}

Although there were some general patterns in how dams affect natural flow, we found that the magnitude and direction of the effects of dams on stream flows is strongly influenced by flow class membership. Flow classes, similar to other geographical stratifications, should reflect climate, geography, and landscape characteristics (McManamay et al., 2011b) and provide the basis for evaluating hydrologic alterations (Arthington et al., 2006). In essence, the central tendency of flow classes provide the starting point from which deviations in the natural flow regime can be measured.

One of the strengths of our study is that we did not limit our analyses to only pre/post regulation data, which could have reduced the sample size and resolution. In contrast, we expanded our analyses to compare various drainages; thus, we had to consider other factors that may confound our analyses, including other hydrologic disturbances. We found that other hydrologic disturbances, especially 

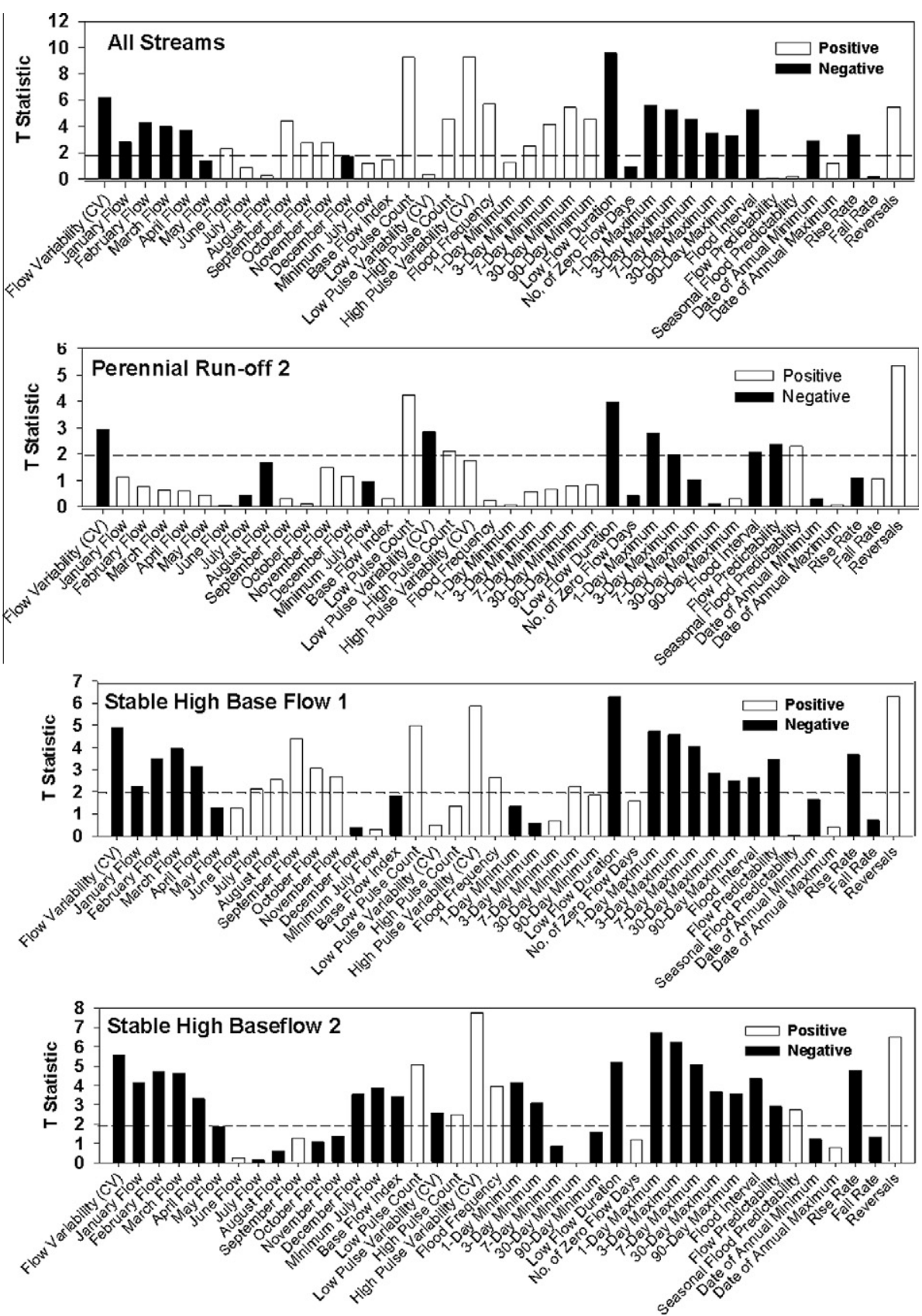

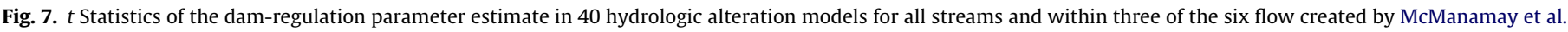

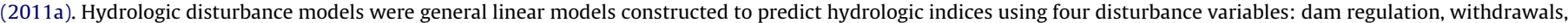

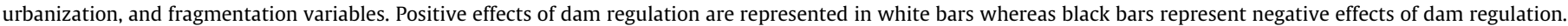
Dashed line indicates the significance of the $t$-statistic for each hydrologic index.

urbanization, can have equally strong influences that may compound or counter the hydrologic effects of dams. Hence, it is apparent that to form broad generalizations concerning certain hydrologic disturbances, the source(s) of hydrologic alteration must be isolated.

\subsection{Pre- and post-regulation analysis}

One of the observations of this study is the disparity in the number of gages with adequate pre- and post-regulation data relative to the total number of regulated gages. Before/after regulation analysis has dominated the literature concerning the effects of dam regulation on natural flow dynamics (Richhter et al., 1996; Magilligan and Nislow, 2001, 2005; Poff et al., 2007; Pyron and Neumann, 2008; Gao et al., 2009). However, gages with adequate pre-regulation data composed less than $50 \%$ of the regulated gages dataset and did not have adequate representatives in all flow classes (Fig. 2). This suggests that only using gages with pre-regulation data to form generalizations may under-represent the overall variability and may limit the analytical power of finer-resolution analyses. Although not all flow classes were represented in our pre/ post analysis, the four flow classes that were represented showed that dams affect river systems differently depending on their pre-existing natural flow regime (Fig. 3).

\subsection{Hydrologic disturbance dataset}

The HDI index provided an assessment of the cumulative hydrologic disturbances within each basin. Interestingly, we found that 

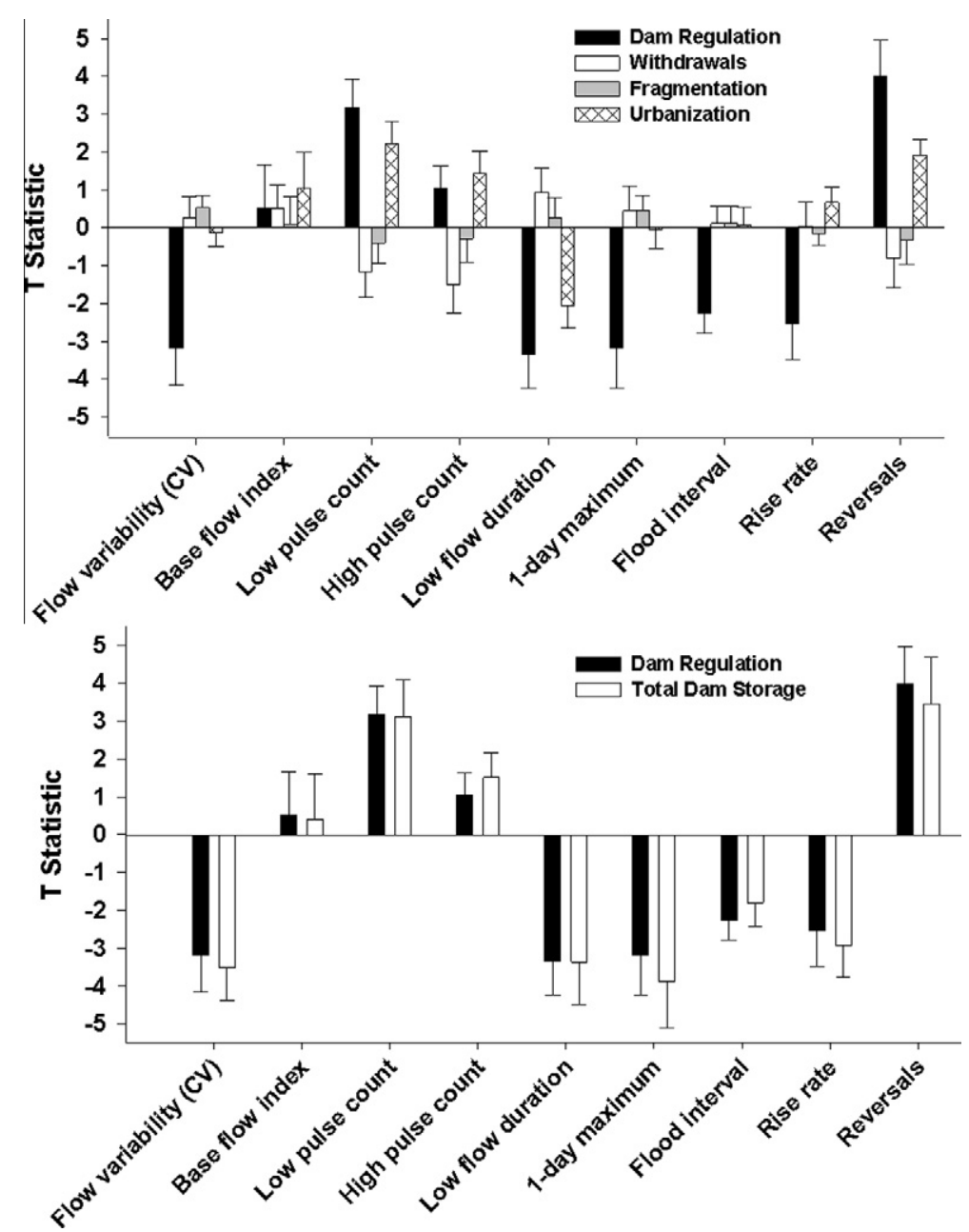

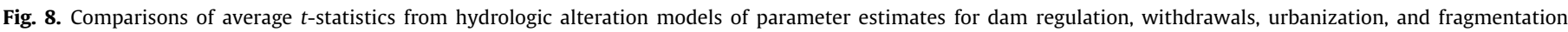

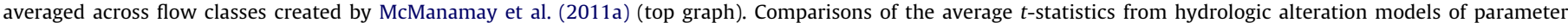

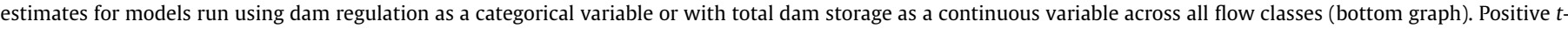

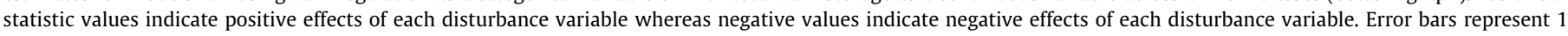
standard error.

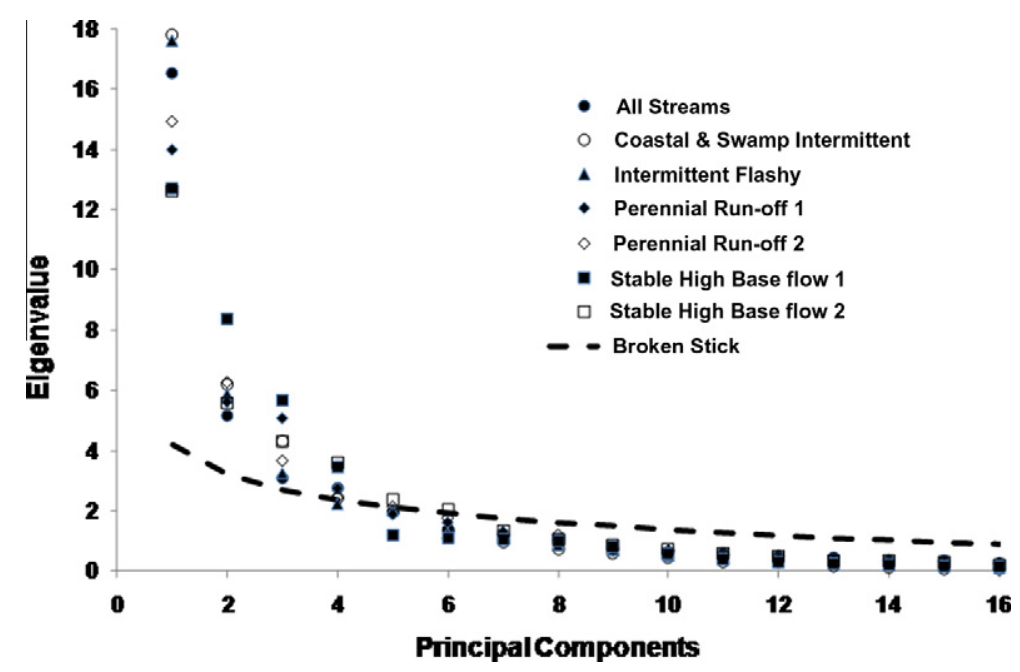

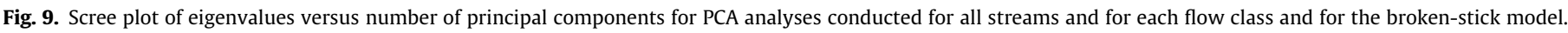
Flow classes created by McManamay et al. (2011a).

both regulated and unregulated rivers showed a large gradient of hydrologic alterations (Fig. 4). Also, pre-regulation gages showed a variety of HDI values, which suggests that even some pre/post analyses may be confounded if studies do not account for other hydrologic disturbances besides dam regulation. Although unregulated streams were dominated by lower HDIs, several unregulated 
Unregulated

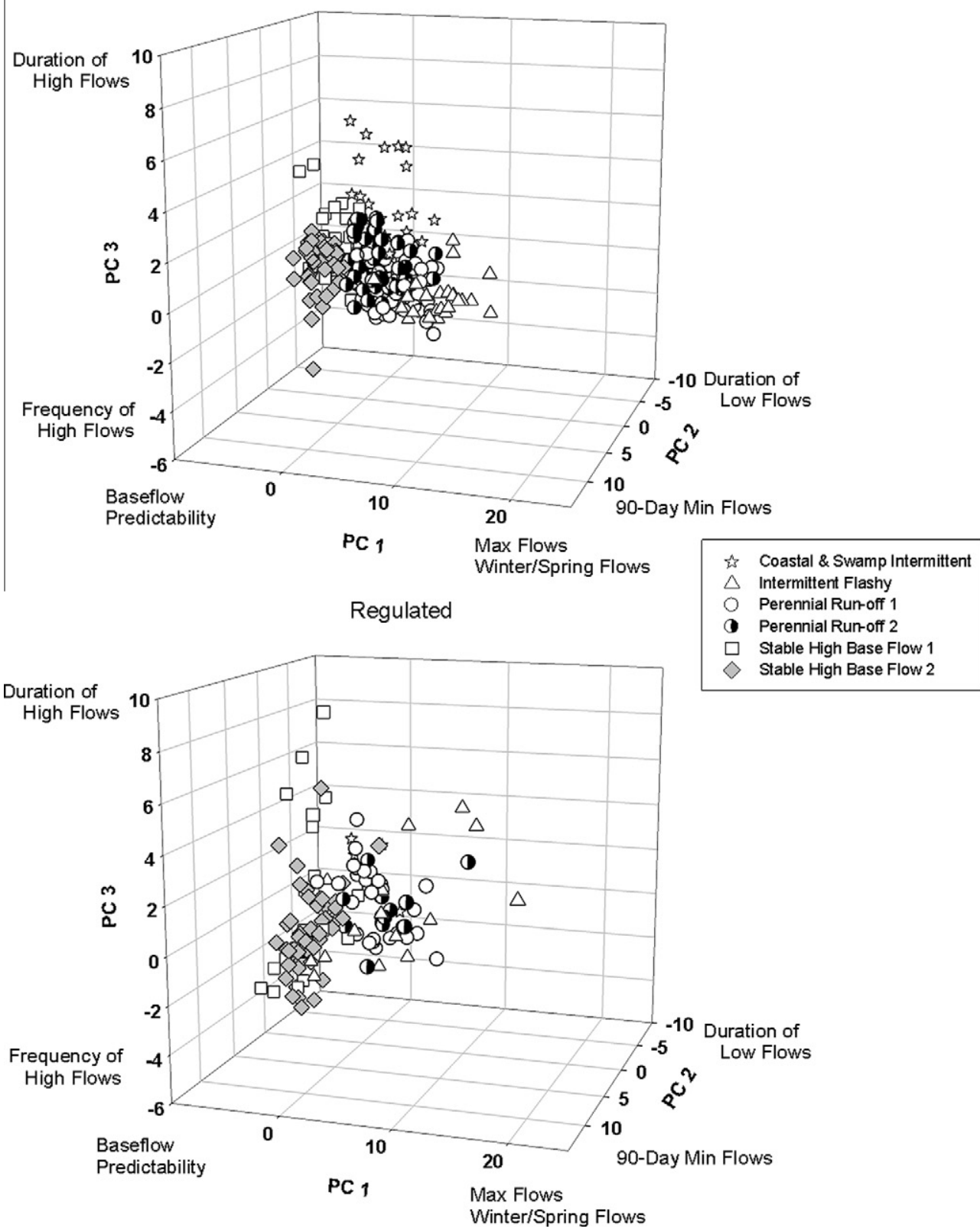

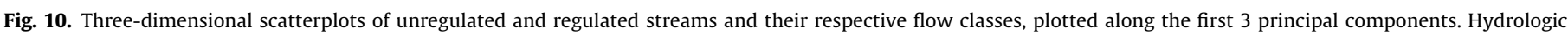
indices with highest loadings are labeled on each of the principal component axes. Flow classes created by McManamay et al. (2011a).

streams had HDIs in the more disturbed categories. This suggests that these few streams were highly disturbed. However, since all variables that compose the disturbance index are weighted equally, there is no structure that influences the relative importance of various disturbance factors. Thus, it is very feasible for unregulated streams to have higher HDIs than regulated streams. For example, the James River, VA is considered regulated because flow in one of its tributaries, the Jackson River, is controlled by Gathright Dam. However, total dam storage along with withdrawal, urbanization, and fragmentation is fairly small in the James River watershed, which leads to a low HDI value. In addition, the HDI does not take into account dam operation type, which may have profound influences on stream hydrology, regardless of total dam storage. Therefore, HDIs may not adequately address the extent of disturbance.
The unregulated stream records in our analyses were taken from the flow classification dataset created by McManamay et al. (2011a) and thus, the most disturbed unregulated streams in the study region had already been removed from the dataset at the outset of the study. Hence, the highest HDI scores do not reflect the most disturbed systems in our region, but only the most disturbed in our dataset. Regardless, ranges in HDI values of unregulated streams suggest that there is a gradient of cumulative hydrologic alterations that should be accounted for in analyses that attempt to isolate the effects of individual disturbances, such as dam regulation. Instead of dodging these confounding disturbances by removing streams from our dataset, appropriate analyses should be conducted to increase the knowledge of how hydrologic alterations influence flow dynamics. 

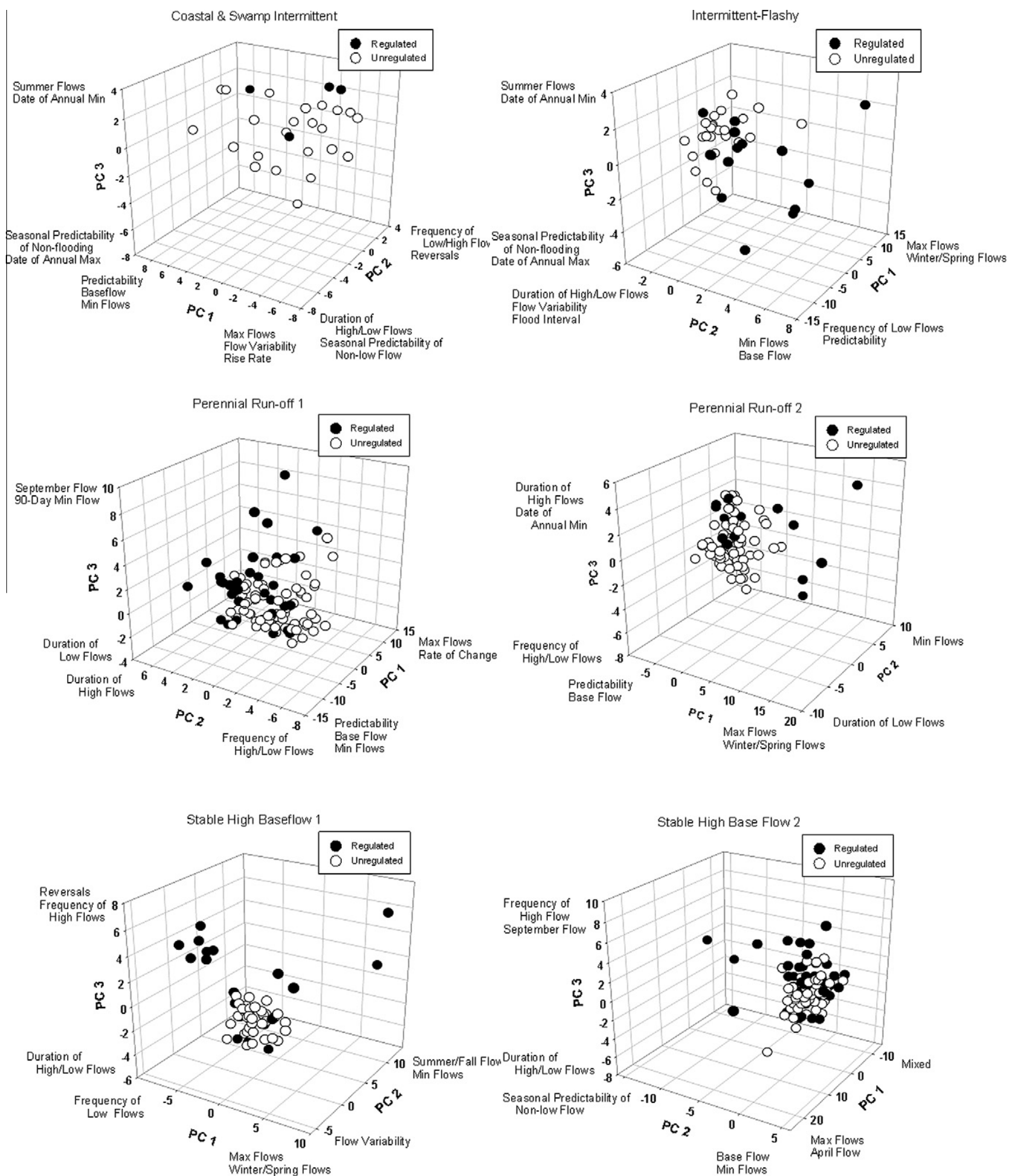

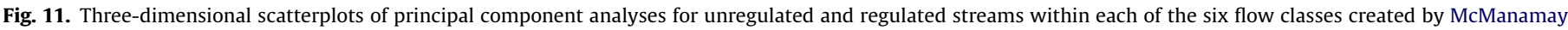

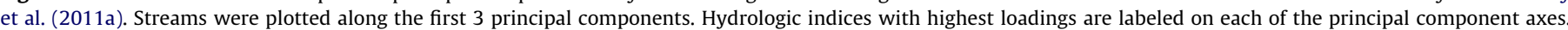

\subsection{Hydrologic disturbance models}

To isolate the effects of dam regulation, we had to control for other factors that may also explain variability in hydrologic indices, such as drainage area and watershed disturbance factors through general linear models. Drainage area explained $0-73 \%$ of the variation in unregulated streams, depending on the hydrologic index and flow class (Table 4). This suggests that our analyses could have been very biased without controlling for drainage area, since dams tend to impound larger river systems. After controlling for drainage area, we found that the mean value of hydrologic response variables among flow classes spanned a large range 
compared to regulation type (Fig. 5). Flow classes represent distinct hydrologic properties (Poff, 1996; McManamay et al., 2011a), but they also represent systems distinguished by different climate, soils, and topography (McManamay et al., 2011b). The large range in variation explained by flow classes suggests that accounting for flow class membership in analyses may control for the natural factors that influence hydrology. Therefore, flow classes were used as a surrogate for geographical differences among basins.

The results of the MANCOVA showed that the effects of flow class membership, dam regulation, urbanization, withdrawals, and fragmentation were all highly significant; however, dam regulation had the largest effect (Table 2). Although the MANCOVA results were informative, they did not provide specific information concerning the individual response of hydrologic variables, especially within different flow classes. Hydrologic disturbance models explained $0-69 \%\left(R^{2} \mathrm{adj}\right.$.) of the variation in hydrologic indices for all streams depending on the individual hydrologic index and flow class (Table 5). In addition, the ranges in $R^{2}$ values suggests that some patterns in hydrologic indices are either not easily generalized or are not influenced by our specific predictor variables whereas other indices showed stronger patterns. Furthermore, this suggests that some prioritization can be made concerning which hydrologic variables to focus attention in hydrologic alteration studies. For example, Gao et al. (2009) isolated a few representative indicators out of the 32 IHA variables that explained the majority of the variation in hydrologic alterations.

Dam regulation explained the majority of variation in $65 \%$ of statistically significant models within flow classes; however urbanization, fragmentation, and withdrawals explained the majority of variation in a substantial number of models (Table 5). Similarly, when compared to other disturbance factors, dam regulation had the largest and most consistent effect on flow across classes (Fig. 8). However, we also found that the effects of urbanization may compound the effects of dam regulation while withdrawals and fragmentation tend to counter them (Fig. 8). Although dam regulation explained up to $39 \%$ of the overall variation in the individual flow class models, fragmentation and urbanization explained up to $35 \%$ and $34 \%$ of the variation in models, respectively (results not shown). Altogether this suggests that not accounting for these factors may have resulted in confounded analyses. Thus, it may be very important to isolate individual disturbances within basins in order to understand how each may alter flow. Despite the compounding and countering effects of other disturbances, we were able to isolate some general patterns in hydrology attributed to dam regulation. For example, dam regulation decreased flow variability, 1-day maximum flows, flood intervals, and rise rates whereas the frequency of low flows and reversals showed increases (Fig. 8). In addition, dam storage gave very similar results to the regulated versus unregulated classification and thus, could be used as a surrogate for dam regulation in general.

Disturbance models showed that the magnitude and the direction of the influence of dam regulation on hydrology vary quite differently depending on the individual hydrologic index and the flow class (Fig. 6 and 7). PR1 streams and the stable high baseflow streams showed the strongest affects of dam regulation; however, this may be associated with higher sample sizes in each of these classes. Across all classes, maximum flows, flow variability, rise rates, low flow durations, and flood intervals generally showed decreases whereas low-flow pulse counts, high-pulse variability, and reversals showed increases, some of which are similar to findings in other studies (Magilligan and Nislow, 2001, 2005; Pyron and Neumann, 2008; Poff et al., 2007) (Table 3). Thus, there are some broad generalizations that can be made concerning the influence of dams on river systems, despite large pre-existing differences (Table 3). Typically, minimum flows show increases following dam regulation (Magilligan and Nislow, 2001, 2005; Pyron and Neumann, 2008; Poff et al., 2007). However, we found that the effect of dams on minimum flows varied depending on class (Table 3). For example, IF and PR1 streams showed positive effects of dam regulation on minimum flow. Yet, the other classes were either impartial or showed strong decreases in minimum flow (e.g. SBF2). Additionally, the effect of dam regulation on baseflows, predictability, and average monthly flows showed inconsistent results across flow classes, but showed stronger results within flow classes. Again, this suggests that rivers may be influenced differently by dams according to their pre-existing natural flow regimes. The fact that flow regimes may be homogenized by dam regulation (Poff et al., 2007) does not insinuate that dams affect all rivers similarly. Rather, homogenization of flow regimes suggests that dams moderate or negate the natural processes responsible for the divergence of flow regimes (Poff et al., 2007). For example, IF, PR1, and PR2 streams showed increases in the annual minimum whereas SBF1 and SBF2 streams show decreases. The result is that, for some individual hydrologic indices, flows within very different river systems may appear more similar following dam regulation.

Although models explained substantial variation for some hydrologic variables, the poor predictive ability of our hydrologic disturbance models for other hydrologic variables suggests that model structure may have been inappropriate given the data (i.e. non-linear relationships). For example, Carlisle et al. (2010a) built regression trees using climate, geologic, soil, topographic, and geographic variables to predict hydrologic indices across the US. The trees were highly accurate compared to static classifications, which suggests that hierarchical structure may have increased model predictive power. However, linear regression models have been used to predict hydrologic indices and have explained substantial amounts of variation in response variables in

Table 3

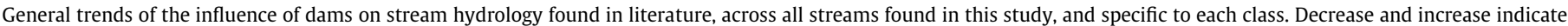
the direction of the influence of dams on each hydrologic variable. All variables included had a t statistics with $p<0.05$.

\begin{tabular}{|c|c|c|}
\hline Entire sample or class & Decrease & Increase \\
\hline Generalizations from literature ${ }^{\mathrm{a}}$ & Maximum flows, flow variability, rise/fall rates & Minimum flows, reversals \\
\hline All classes (this study) & $\begin{array}{l}\text { Maximum flows, flow variability, rise rate, low flow } \\
\text { duration, flood interval }\end{array}$ & Reversals, low flow pulse counts, high pulse variability \\
\hline Intermittent-flashy & Spring flows & Minimum flows, baseflow index, flow predictability, flood frequency \\
\hline Perennial run-off 1 & February flow, seasonal flood predictability & $\begin{array}{l}\text { Minimum flows, baseflow index, fall flows, June flow, flood } \\
\text { frequency, date of annual maximum, flow predictability }\end{array}$ \\
\hline Perennial run-off 2 & Low pulse variability, flow predictability & High pulse count, seasonal flood predictability \\
\hline Stable high baseflow 1 & Winter/spring flows, flow predictability & Summer/fall flows, flood frequency \\
\hline Stable high baseflow 2 & $\begin{array}{l}\text { Winter/spring flows, minimum flows, baseflow index, } \\
\text { low pulse variability, flow predictability }\end{array}$ & High pulse count, flood frequency, seasonal flood predictability \\
\hline
\end{tabular}

${ }^{\text {a }}$ Richhter et al. (1996), Magilligan and Nislow (2001), Magilligan and Nislow (2005), Pyron and Neumann (2008) and Poff et al. (2007). 
various regions (DeWalle et al., 2000; Sanborn and Bledsoe, 2006; Mohamoud, 2008; Zhu and Day, 2009). Another potential source of unexplained variability was the exclusion of local factors (e.g. soil, climate) that may have been important in predicting hydrologic indices. We used flow classes as a stratification to control for climate, geology, and topography and then developed disturbance linear models separately for each class. Similarly, Sanborn and Bledsoe (2006) stratified basins in Colorado by major differences in flow regime and geography and developed separate linear regressions to predict streamflow metrics for each type. However, climate, geomorphology, and soil factors may exert various localized controls on hydrology, depending on regional affiliation (Mohamoud, 2008). Thus, including natural factors in hydrologic alteration models may have increased our predictive ability. One limitation, however, was that the number of predictors in models were limited given the sample size in each class.

\subsection{Overall variation in flow dynamics of regulated and unregulated streams}

The results of the PCA suggested that dam regulation pushed the flowing environment outside the bounds of normal river function rather than homogenizing river flows. Furthermore, this would also suggest that the cumulative effects of dams on the multi-dimensional fluvial habitats creates environments to which endemic riverine biota are maladapted (Poff et al., 1997; Bunn and Arthington, 2002). We hypothesized that in a multivariate analysis, such as PCA, the effects of homogenization would be manifested by regulated streams showing higher correlative structure and occupying a smaller multivariate space (i.e. less divergence) than their unregulated counterparts. However, we found that unregulated streams were actually highly correlated and filled a more confined multivariate space relative to regulated streams, which occupied a larger multivariate area with more random spread (Figs. 10 and 11). Thus, in the multivariate sense, stream hydrology does not appear to be homogenized by dams. However, this may reflect the fact that we used 38 variables in the PCA rather than a fewer number of dominant hydrologic indices that exert a larger relative influence on river function and habitats. If those dominant hydrologic indices tend to be stabilized by dam regulation, as in the case of maximum flows and rise rates, then in an ecologically meaningful sense, rivers may be homogenized by dams.

The fact that the flow regime is a multivariate term is not a new concept (Poff et al., 1997). Free-flowing streams are subject to natural constraints in hydrology; that is, there are typical reoccurring patterns and relationships among hydrologic variables (Leopold, 1994), which lead to correlative structure. For example, streams characterized by intermittency will most likely have high daily variability, high flood frequency, and rapid rise rates (Poff, 1996; McManamay et al., 2011a). In regulated streams, dams impose unnatural constraints on river systems and break the typical reoccurring hydrologic pattern, which leads to poor correlations among hydrologic variables. Thus, even if some hydrologic variables respond similarly to dam regulation, the fact that other variables respond differently or do not respond at all will cause low correlative structure. In addition, the starting point of divergence from the norm (i.e. flow class) may be far different despite a similar direction in the response of hydrologic variables.

Similar to our evaluation of individual hydrologic indices, dam regulation affected the overall variability in flow differently depending on flow class. Not surprisingly, different hydrologic indices had the highest loadings for different flow classes. Thus, in terms of providing environmental flow standards for altered systems, it may be important to evaluate different subsets of hydrologic variables that are relevant to each flow class (Olden and Poff, 2003). Interestingly, the PCA showed that some regulated rivers were embedded in the multivariate space of unregulated rivers whereas others showed extensive divergence (Fig. 11). Examining the multivariate structure of flow dynamics may provide a framework to isolate systems that are the most altered, which should have implications for ecological relationships and management. For example, systems that show large hydrologic alterations may also display major shifts in fish or macroinvertebrate assemblages (Bunn and Arthington, 2002) and losses in native fauna (Moyle and Mount, 2007).

There are a few limitations of our analyses that may have influenced the dispersion of streams in the PCA. One source of uncertainty is that the disturbances responsible for the divergence in some of the regulated streams may have been induced by other factors besides dam regulation. However, the range of HDI values indicates that regulated and unregulated streams were subject to a variety of disturbances. Furthermore, the variation in HDI values for unregulated streams were higher than that of regulated streams. In order to account for differences in disturbances, appropriate analyses, such as model building (this study) or basin-specific historical reconstructions of stream flow (Vogl and Lopes, 2009), may be needed to separate confounding effects of various watershed disturbances. Another potential source of dispersion in regulated streams is that some regulated streams were impounded by more than 1 dam. However, if the homogenization-by-dams principle holds true, then we would expect that variability would decrease with consecutive impoundments. Misclassifying regulated streams could be an additional source of variation. However, given the accuracy rates of our predictive tools, we expect misclassification rates to be minor. Furthermore, 32\% of our regulated gages had pre-regulation hydrologic information that was used in the flow classification by McManamay et al. (2011a). Thus, these regulated stream records were already assigned to correct classes.

\subsection{Potential for restoring regulated river flows}

Due to the social, economic, political, and ecological complexities of managing for natural flow variability in rivers with altered hydrology, most flow rules have been limited to overly simplified or overly generalized standards (Arthington et al., 2006). It is now widely accepted that sustainable water management in river systems will require abandoning static water allocation strategies and adopting strategies that protect the magnitude, frequency, duration, timing, and rate of change in flow (Poff et al., 1997; Arthington et al., 2006; Richter, 2010). New policies will require establishing socially acceptable sustainability boundaries that protect the ecological integrity of river systems (Richter, 2010). Flow classifications provide a less complex approach to management by establishing environmental flow standards for groups of streams that share similar hydrology rather than managing for the individuality of every river system. The range of variability represented in flow classes should provide the structure from which boundaries or limits to hydrologic alteration are established. According to Poff et al. (2010), influencing the societal and political driven process of developing regional flow standards to protect natural flow regimes will require developing generalized relationships between altered flow regimes and ecology. Our results suggest that rivers in different flow classes may respond differently to a single type of disturbance. Furthermore, we presume that rivers within a particular flow class may also share similar ecological properties as well as similar ecological responses to altered flow conditions (Poff et al., 2010). In summary, flow classifications, on a regional scale, should provide the baselines from which 
departures or hydrologic alterations are measured. These classes then provide the context for generalizing hydrologic alterations, evaluating ecological responses, and developing environmental flow standards.

\section{Conclusions}

The framework we have presented for generalizing patterns in hydrologic alteration may be more important than the results discussed herein. The approach that we have outlined could provide a framework to form accurate generalizations concerning not only the effect of dam regulation but also other anthropogenic disturbances on stream flows. In addition, the approach is not limited to only pre- and post-disturbance analyses. This approach also can provide environmental flow standards for regulated systems that lack sufficient pre-disturbance hydrologic information. In addition, the framework could be modified to predict hydrologic alterations in basins without any discharge information. The ability to create frameworks that incorporate river systems with insufficient or no hydrologic information is critical to increasing the resolution of relationships between ecology and altered hydrology (Knight et al., 2008)
Scientists and managers benefit from organizing data into pieces of digestible information. Natural flow classes represent differences in flow that are the result of climate, geographical, and landscape-driven processes, which may provide a suitable framework for organizing information into more meaningful analyses (McManamay et al., 2011b). In analyses evaluating hydrologic alterations, flow classes could provide the primary structure followed by geomorphological classes as a secondary stratification (Poff et al., 2006b). In addition, regulation type (dam operation context) or other hydrologic disturbance types can be used to further stratify analyses and increase predictive ability. Classifying groups of streams with similar hydrologic properties will aid in modifying policies by providing management units that share similar environmental flow standards thereby protecting aspects of the natural flow regime. On a state-by-state basis, flow classifications have been conducted in response to statewide water planning (Turton et al., 2008) and as a statewide protocol to develop environmental flow standards (Kennen et al., 2007, 2009). However, water supply plans for most states in our study area typically do not mention managing water quantity or quality on the basis of natural flow variability (NCDENR 2001; Badr et al., 2009; GWC, 2008). Our results suggest that streams that are hydrologically

Table 4

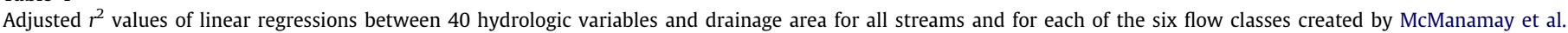
(2011a,b). Hydrologic variables and drainage area were $\log (x+1)$ transformed prior to analysis. If no values are present, then $R^{2}$ equals 0 .

\begin{tabular}{|c|c|c|c|c|c|c|c|}
\hline & All & $\begin{array}{l}\text { Coastal and swamp } \\
\text { intermittent }\end{array}$ & $\begin{array}{l}\text { Inte rmitte } \\
\text { nt flashy }\end{array}$ & $\begin{array}{l}\text { Perennial } \\
\text { run-off } 1\end{array}$ & $\begin{array}{l}\text { Perennial } \\
\text { run-off } 2\end{array}$ & $\begin{array}{l}\text { Stable high } \\
\text { baseflow } 1\end{array}$ & $\begin{array}{l}\text { Stable high base } \\
\text { flow } 2\end{array}$ \\
\hline No. unregulated streams & 284 & 22 & 19 & 80 & 71 & 37 & 55 \\
\hline Daily flow variability (CV) & $0.08^{* * * *}$ & $0.48^{* * *}$ & & $0.21^{* * *}$ & $0.04^{*}$ & & \\
\hline January flow & & $0.25^{* *}$ & & $0.06^{*}$ & & & $0.14^{* *}$ \\
\hline Fe bruary flow & & 0.06 & & 0.04 & & & $0.15^{* *}$ \\
\hline March flow & & 0.10 & 0.11 & $0.09^{* *}$ & & & $0.08^{*}$ \\
\hline April flow & 0.01 & 0.11 & 0.10 & $0.08^{* *}$ & & & \\
\hline May flow & $0.02^{*}$ & $0.22^{*}$ & & $0.12^{* *}$ & & 0.03 & \\
\hline June flow & $0.09^{* * * *}$ & 0.03 & & $0.08^{* *}$ & & 0.01 & $0.03^{*}$ \\
\hline July flow & & & & & & & 0.02 \\
\hline August flow & & & & $0.05^{*}$ & & $0.39^{* * *}$ & 0.05 \\
\hline Se pte mbe $r$ flow & $0.04^{* *}$ & $0.15^{*}$ & 0.02 & 0.01 & 0.01 & $0.09^{*}$ & $0.07^{*}$ \\
\hline October flow & $0.04^{* * * *}$ & $0.20^{*}$ & & & & $0.09^{*}$ & $0.10^{*}$ \\
\hline November flow & $0.16^{* * * *}$ & $0.73^{* * *}$ & & $0.24^{* * *}$ & $0.05^{*}$ & & $0.29^{* * *}$ \\
\hline December flow & $0.03^{* *}$ & $0.33^{* *}$ & & $0.26^{* * * *}$ & & & \\
\hline Minimum July flow & & $0.59^{* * *}$ & & $0.12^{* * *}$ & & $0.07^{*}$ & 0.04 \\
\hline Base flow index & 0.01 & $0.56^{* * *}$ & & $0.10^{* *}$ & & & $0.10^{*}$ \\
\hline Low pulse count & & 0.07 & 0.02 & 0.03 & & & $0.06^{*}$ \\
\hline Low pulse variability (CV) & $0.01^{*}$ & & & 0.01 & 0.03 & $0.11^{*}$ & 0.03 \\
\hline High pulse count & $0.06^{* * *}$ & $0.22^{*}$ & 0.15 & $0.08^{*}$ & & 0.01 & 0.02 \\
\hline High pulse variability (CV) & & & & & & $0.10^{*}$ & 0.01 \\
\hline Flood frequency & $0.02^{* *}$ & & $0.16^{*}$ & $0.05^{*}$ & & 0.01 & \\
\hline 1-Day minimum & & $0.55^{* * *}$ & & $0.06^{*}$ & & & $0.12^{* *}$ \\
\hline 3-Day minimum & & $0.54^{* * *}$ & & $0.07^{*}$ & 0.02 & & $0.07^{*}$ \\
\hline 7-Day minimum & & $0.53^{* * *}$ & & $0.08^{*}$ & & & 0.05 \\
\hline 30-Day minimum & & $0.45^{* * *}$ & & $0.10^{* *}$ & & 0.01 & $0.06^{*}$ \\
\hline 90-Day minimum & & $0.24^{*}$ & & $0.05^{*}$ & & $0.21^{* *}$ & \\
\hline Low flow duration & 0.01 & $0.18^{*}$ & & $0.06^{*}$ & & & 0.03 \\
\hline No. of zero flow days & $0.03^{* *}$ & & & & & & \\
\hline 1-Day maximum & $0.13^{* * * *}$ & $052^{* * * *}$ & & $0.24^{* * * *}$ & $0.07^{*}$ & & $0.09^{*}$ \\
\hline 3-Day maximum & $0.05^{\text {**** }}$ & $0.48^{* * *}$ & & $0.11^{* * *}$ & & & \\
\hline 7-Day maximum & $0.02^{*}$ & $0.42^{* *}$ & & $0.07^{*}$ & & & \\
\hline 30-Day maximum & 0.01 & $0.24^{*}$ & 0.01 & $0.07^{*}$ & & & $0.08^{*}$ \\
\hline 90-Day maximum & & $0.19^{*}$ & 0.02 & $0.08^{*}$ & & & $0.10^{*}$ \\
\hline Flood interval & $0.01^{*}$ & 0.06 & & & $0.05^{*}$ & 0.01 & $0.14^{* *}$ \\
\hline Flow predictability & $0.44^{* * *}$ & $0.70^{* * *}$ & $0.19^{*}$ & $0.67^{* * *}$ & $0.69^{* * *}$ & $0.45^{* * *}$ & $0.66^{* * *}$ \\
\hline Seasonal flood predictability & $0.04^{* * * *}$ & 0.03 & $0.24^{*}$ & & & & $0.12^{* *}$ \\
\hline Date of annual minimum & $0.03^{* *}$ & 0.09 & $0.24^{*}$ & $0.06^{*}$ & $0.06^{*}$ & 0.03 & $021^{* * *}$ \\
\hline Date of annual maximum & 0.01 & 0.05 & & & & & 0.04 \\
\hline Rise rate & $0.16^{\text {**** }}$ & $052^{* * * *}$ & & $0.38^{* * * *}$ & $0.14^{* *}$ & & $0.21^{* * *}$ \\
\hline Fall rate & $0.09^{* * * *}$ & $0.34^{* *}$ & & $0.24^{* * * *}$ & $0.08^{*}$ & & \\
\hline Reversals & $0.01^{*}$ & $0.32^{* *}$ & & & 0.03 & & $0.03^{*}$ \\
\hline
\end{tabular}

\footnotetext{
* Model significance at the 0.05 level.

** Model significance at the 0.005 level.

*** Model significance at the 0.0005 level.
} 
distinct will respond differently to disturbance. Thus, an obvious conclusion is that streams should be not be managed based upon their locations with various geographic or political boundaries but based upon similar hydrologic properties. We suggest that regional flow management should be based on developing natural hydrologic baselines (e.g. flow classes) for groups of streams rather than region-wide water allocation policies or static minimum flow policies for reservoir operations. In addition, generalizing the hydrological and ecological response of rivers to disturbance should isolate management applications that are suitable to the different needs of diverse river systems.

Overall, dam regulation exerted the strongest and most consistent influences on flow dynamics compared to other disturbance variables. However, for some hydrologic indices, other disturbances in a basin may compound or counter the influences of dam regulation. Analyses should isolate the various contributors to overall hydrologic alteration. Information and large datasests concerning hydrology and lanscape-scale variables are now more readily available than ever (e.g. Falcone et al., 2010, Wollock et al., 2004). Thus, there is great potential to understand general patterns in hydrologic alterations across the landscape.

\section{Acknowledgements}

This work was funded by the Cheoah Fund Board, a multi-agency collaboration between Alcoa Power, USDA Forest Service, US Fish and Wildlife Service, North Carolina Wildlife Resources Commission, and the NC Division of Water Resources-DENR and other grants provided by the USDA Forest Service. We are thankful for the valuable input from Paul Angermeier and Emmanuel Frimpong regarding statistical procedures and study design. We are also thankful for useful comments by two anonymous reviewers that improved this manuscript. Assistance with stream gage data compilation and management was provided by Tyler Young and Adam Hart.

\section{Appendix A}

See Table 4.

\section{Appendix B}

See Table 5.

Table 5

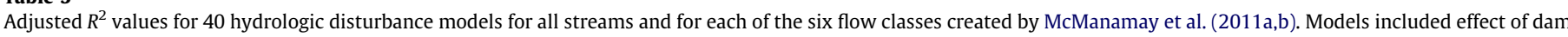

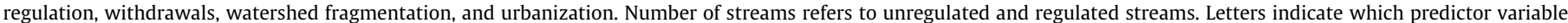
explained the most variation in each model $\left(\mathrm{r}=\right.$ dam regulation, $\mathrm{w}=$ withdrawals, $\mathrm{f}=$ fragmentation, $\mathrm{u}=$ urbanization). If no values are present, then $R^{2}$ equals 0 .

\begin{tabular}{|c|c|c|c|c|c|c|c|c|c|c|c|c|c|c|}
\hline Hydrologic disturbance model & All & & $\begin{array}{l}\text { Coastal and swamp } \\
\text { intermittent }\end{array}$ & & $\begin{array}{l}\text { Intermittent } \\
\text { flashy }\end{array}$ & & $\begin{array}{l}\text { Perennial } \\
\text { run-off } 1\end{array}$ & & $\begin{array}{l}\text { Perennial } \\
\text { run-off } 2\end{array}$ & & $\begin{array}{l}\text { Stable high } \\
\text { baseflow } 1\end{array}$ & & $\begin{array}{l}\text { Stable high } \\
\text { baseflow } 2\end{array}$ & \\
\hline Number of streams & 401 & & 26 & & 30 & & 111 & & 84 & & 54 & & 96 & \\
\hline Daily flow variability (CV) & $0.13^{* * * *}$ & $\mathrm{r}$ & & & $0.46^{* *}$ & $r$ & 0.05 & $\mathrm{r}$ & $0.07^{*}$ & $\mathrm{r}$ & $0.33^{* * *}$ & $\mathrm{r}$ & $0.25^{* * *}$ & $\mathrm{r}$ \\
\hline January flow & $0.08^{* * * *}$ & w & $0.12^{* *}$ & $\mathrm{f}$ & 0.26 & $\mathrm{u}$ & 0.02 & $\mathrm{u}$ & 0.10 & w & 0.08 & $\mathrm{r}$ & 0.15 & $\mathrm{r}$ \\
\hline February flow & $0.10^{* * * *}$ & w & 0.07 & $\mathrm{f}$ & 0.29 & $\mathrm{u}$ & 0.06 & r & 0.07 & w & 0.15 & $\mathrm{r}$ & 0.20 & $r$ \\
\hline March flow & $0.09^{* * *}$ & w & 0.16 & f & 0.28 & $\mathrm{u}$ & & & 0.04 & w & 0.20 & $\mathrm{r}$ & 0.18 & $r$ \\
\hline April flow & $0.08^{* * * *}$ & w & 0.27 & $\mathrm{f}$ & 0.27 & $\mathrm{u}$ & & & 0.05 & $\mathrm{f}$ & 0.13 & $\mathrm{r}$ & 0.09 & $\mathrm{r}$ \\
\hline May flow & $0.02^{*}$ & w & 0.17 & f & 0.16 & $\mathrm{u}$ & & & 0.02 & $\mathrm{f}$ & & & 0.02 & $r$ \\
\hline June flow & $0.04^{* * *}$ & $\mathrm{f}$ & 0.02 & $r$ & 0.17 & $\mathrm{u}$ & $0.13^{* * *}$ & $r$ & $0.11^{*}$ & $\mathrm{u}$ & 0.04 & $\mathrm{u}$ & 0.07 & $\mathrm{f}$ \\
\hline July flow & $0.07^{* * * *}$ & w & & & 0.24 & w & 0.07 & $\mathrm{u}$ & 0.23 & w & 0.18 & $\mathrm{f}$ & 0.10 & w \\
\hline August flow & $0.07^{* * * *}$ & $\mathrm{f}$ & & & 0.12 & $\mathrm{f}$ & 0.04 & w & 0.10 & w & 0.17 & $\mathrm{r}$ & 0.01 & $\mathrm{w}$ \\
\hline September flow & $0.23^{* * * *}$ & $\mathrm{f}$ & 0.08 & $\mathrm{f}$ & 0.24 & $\mathrm{u}$ & $0.32^{* * * *}$ & $\mathrm{r}$ & 0.11 & $\mathrm{f}$ & 0.33 & $\mathrm{r}$ & 0.04 & $\mathrm{f}$ \\
\hline October flow & $0.17^{* * * *}$ & $\mathrm{f}$ & $0.43^{*}$ & $\mathrm{f}$ & & & 0.15 & $\mathrm{r}$ & 0.01 & $\mathrm{u}$ & 0.23 & $r$ & $0.26^{* *}$ & $\mathrm{f}$ \\
\hline November flow & $0.08^{* * * *}$ & $\mathrm{f}$ & 0.28 & $\mathrm{r}$ & $0.32^{* *}$ & $\mathrm{u}$ & 0.20 & $\mathrm{r}$ & 0.02 & $r$ & 0.24 & f & 0.19 & $\mathrm{w}$ \\
\hline Decemberflow & $0.05^{* * *}$ & w & & & 0.33 & $\mathrm{u}$ & & & 0.06 & w & 0.09 & f & 0.13 & $\mathrm{r}$ \\
\hline Minimum July flow & $0.05^{* * *}$ & $\mathrm{u}$ & & & 0.28 & $\mathrm{r}$ & $0.09^{* * *}$ & $\mathrm{r}$ & 0.16 & $\mathrm{u}$ & 0.12 & $\mathrm{f}$ & 0.18 & $\mathrm{r}$ \\
\hline Base flow index & $0.06^{* * * *}$ & $\mathrm{u}$ & & & $0.69^{*}$ & $\mathrm{u}$ & 0.10 & $r$ & 0.06 & $\mathrm{u}$ & 0.01 & $r$ & 0.18 & $\mathrm{r}$ \\
\hline Low pulse count & $0.25^{* * *}$ & $r$ & $0.41^{* *}$ & w & 0.41 & $\mathrm{u}$ & 0.15 & $\mathrm{u}$ & $0.23^{*}$ & $r$ & $0.37^{* * *}$ & $\mathrm{r}$ & 0.21 & $r$ \\
\hline Low pulse variability (C V) & $0.04^{* * * *}$ & $\mathrm{f}$ & 0.31 & w & 0.17 & w & 0.10 & $\mathrm{f}$ & 0.09 & $\mathrm{r}$ & 0.09 & $\mathrm{w}$ & 0.10 & $r$ \\
\hline High pulse count & $0.10^{* * *}$ & $\mathrm{r}$ & 0.19 & w & 0.33 & $\mathrm{u}$ & 0.01 & $\mathrm{f}$ & 0.09 & $\mathrm{r}$ & $0.36^{*}$ & $\mathrm{w}$ & 0.12 & $\mathrm{r}$ \\
\hline High pulse variability (CV) & $0.19^{* * * *}$ & $\mathrm{r}$ & 0.02 & $\mathrm{f}$ & 0.50 & $r$ & $0.23^{* * *}$ & $\mathrm{r}$ & 0.02 & $r$ & 0.43 & $r$ & $0.38^{*}$ & $\mathrm{r}$ \\
\hline Flood frequency & $0.08^{* * * *}$ & $r$ & 0.16 & w & 0.20 & $\mathrm{r}$ & 0.07 & $\mathrm{r}$ & & & 0.07 & $\mathrm{r}$ & 0.12 & $\mathrm{r}$ \\
\hline 1-Day minimum & $0.04^{* * *}$ & $\mathrm{u}$ & & & $0.51^{*}$ & $\mathrm{u}$ & 0.14 & $\mathrm{r}$ & $0.08^{* * *}$ & $\mathrm{u}$ & 0.05 & $\mathrm{w}$ & 0.27 & $\mathrm{r}$ \\
\hline 3-Day minimum & $0.07^{* * * *}$ & $\mathrm{u}$ & & & 0.62 & $\mathrm{u}$ & 0.15 & $\mathrm{r}$ & 0.09 & $\mathrm{u}$ & 0.03 & w & 0.21 & $\mathrm{f}$ \\
\hline 7-Day minimum & $0.10^{* * * *}$ & $\mathrm{u}$ & & & 0.66 & $r$ & 0.16 & $\mathrm{r}$ & 0.11 & $\mathrm{u}$ & 0.04 & $\mathrm{w}$ & 0.11 & $\mathrm{f}$ \\
\hline 30-Day minimum & $0.15^{* * *}$ & $r$ & 0.10 & $\mathrm{r}$ & 0.67 & $\mathrm{u}$ & 0.21 & $\mathrm{r}$ & 0.19 & $\mathrm{u}$ & 0.16 & $r$ & 0.11 & $\mathrm{f}$ \\
\hline 90-Day minimum & $0.15^{* * *}$ & $\mathrm{u}$ & 0.23 & $\mathrm{f}$ & 0.25 & w & 0.19 & $\mathrm{r}$ & 0.33 & $\mathrm{u}$ & 0.16 & f & 0.11 & $\mathrm{f}$ \\
\hline Low flow duration & $0.26^{* * * *}$ & $r$ & 0.32 & $\mathrm{r}$ & 0.34 & $\mathrm{u}$ & 0.15 & $\mathrm{u}$ & 0.23 & $r$ & $0.46^{*}$ & $r$ & 0.23 & $\mathrm{r}$ \\
\hline No. of zero flow days & $0.07^{* * * *}$ & $\mathrm{f}$ & & & 0.46 & $\mathrm{u}$ & & & & & & & & \\
\hline 1-Day maximum & $0.11^{* * * *}$ & $\mathrm{r}$ & & & 0.42 & $r$ & 0.04 & $\mathrm{r}$ & $0.07^{*}$ & $r$ & $0.31^{* * * *}$ & $\mathrm{r}$ & $0.33^{* * *}$ & $r$ \\
\hline 3-Day maximum & $0.12^{* * * *}$ & $\mathrm{r}$ & & & 0.39 & $r$ & 0.01 & $\mathrm{r}$ & 0.04 & w & 0.27 & $\mathrm{r}$ & 0.29 & $\mathrm{r}$ \\
\hline 7-Day maximum & $0.12^{* * * *}$ & $r$ & & & 0.35 & $\mathrm{u}$ & & & 0.03 & w & 0.22 & $r$ & 0.20 & $\mathrm{r}$ \\
\hline 30-Day maximum & $0.09^{* * * *}$ & w & $0.14^{* *}$ & $\mathrm{f}$ & 0.32 & $\mathrm{u}$ & & & 0.03 & w & 0.11 & $\mathrm{r}$ & 0.09 & $r$ \\
\hline 90-Day maximum & $0.08^{* * * *}$ & w & 0.15 & $\mathrm{f}$ & 0.31 & $\mathrm{u}$ & & & 0.04 & w & 0.07 & $\mathrm{r}$ & 0.09 & $\mathrm{r}$ \\
\hline Flood interval & $0.08^{* * * *}$ & $\mathrm{r}$ & 0.07 & $r$ & 0.13 & $r$ & & & 0.13 & $\mathrm{u}$ & 0.08 & $\mathrm{r}$ & 0.16 & $\mathrm{r}$ \\
\hline Flowpredictability & $0.12^{* * *}$ & f & 0.05 & w & $0.59^{* *}$ & $\mathrm{u}$ & $0.04^{* * *}$ & $\mathrm{r}$ & 0.06 & $r$ & $0.30^{*}$ & $\mathrm{r}$ & 0.07 & $\mathrm{r}$ \\
\hline Seasonal flood predictability & $0.06^{* * * *}$ & $\mathrm{f}$ & 0.08 & $\mathrm{f}$ & 0.12 & $\mathrm{u}$ & 0.04 & $\mathrm{r}$ & 0.17 & $\mathrm{u}$ & & & 0.16 & $\mathrm{f}$ \\
\hline Date of annual minimum & $0.10^{* * *}$ & $\mathrm{r}$ & 0.29 & f & & & & & 0.06 & $\mathrm{u}$ & & & & \\
\hline Date of annual maximum & & & & & 0.06 & $\mathrm{u}$ & $0.09^{* *}$ & $\mathrm{r}$ & 0.03 & $\mathrm{u}$ & 0.01 & f & & \\
\hline Rise rate & $0.04^{* * * *}$ & $\mathrm{r}$ & & & $0.37^{*}$ & $r$ & 0.02 & $\mathrm{r}$ & 0.03 & w & $0.31^{* * *}$ & $\mathrm{r}$ & $0.22^{* * *}$ & $\mathrm{r}$ \\
\hline Fafl rate & $0.04^{* *}$ & $\mathrm{f}$ & & & 0.11 & $r$ & & & 0.09 & w & 0.15 & $\mathrm{w}$ & 0.03 & $\mathrm{u}$ \\
\hline Reversals & $0.26^{* * *}$ & $r$ & $0.24^{*}$ & $r$ & $0.43^{*}$ & $\mathrm{u}$ & $0.08^{* * *}$ & $\mathrm{u}$ & $0.35^{* *}$ & $r$ & $0.50^{* *}$ & $r$ & $0.34^{* * *}$ & $r$ \\
\hline
\end{tabular}

* Model significance at the 0.05 level.

** Model significance at the 0.005 level.

Model significance at the 0.0005 level. 


\section{Appendix A. Supplementary material}

Supplementary data associated with this article can be found, in the online version, at doi:10.1016/j.jhydrol.2012.01.003.

\section{References}

Arthington, A.H., Bunn, S.E., Poff, N.L., Naiman, R.J., 2006. The challenge of providing environmental flow rules to sustain river systems. Ecol. Appl. 16, 1311-1318.

Badr, A.W., Wachob, A., Gellici, J.A., 2009. South Carolina Water Plan, second ed. South Carolina Department of Natural Resources. <http://www.dnr.state.sc.us/

Brown, D.G., Johnson, K.M., Loveland, T.R., Theobald, D.M., 2005. Rural land-use trends in the conterminous United States, 1950-2000. Ecol. Appl. 15, 18511863.

Bunn, S.E., Arthington, A.H., 2002. Basic principles and ecological consequences of altered flow regimes for aquatic biodiversity. Environ. Manage. 30, 492-507.

Carlisle, D.M., Falcone, J., Wolock, D.M., Meador, M.R., Norris, R.H., 2010a. Predicting the natural flow regime: models for assessing hydrological alteration in streams. River Res. Appl. 26, 118-136.

Carlisle, D.M., Wollock, D.M., Meador, M.R., 2010b. Alteration of streamflow magnitudes and potential ecological consequences: a multiregional assessment. Front. Ecol. Environ. 2010. doi:10.1890/100053.

DeWalle, D.R., Swistock, B.R., Johnson, T.E., McGuire, K.J., 2000. Potential effects of climate change and urbanization on mean annual streamflow in the United States. Water Resour. Res. 36, 2655-2664.

Falcone, J.A., Carlisle, D.M., Wolock, D.M., Meador, M.R., 2010. GAGES: a stream gage database for evaluating natural and altered flow conditions in the conterminous United States. Ecology, 91, 621 (Ecol. Arch. E091-045-D1).

Gao, Y.X., Vogel, R.M., Kroll, C.N., Poff, N.L., Olden, J.D., 2009. Development of representative indicators of hydrologic alteration. J. Hydrol. 374, 136-147.

Graf, W.L., 1999. Dam nation: a geographic census of American dams and their large-scale hydrologic impacts. Water Resour. Res. 35, 1305-1311.

Georgia Water Council (GWC), 2008. Georgia Comprehensive State-wide Water Management Plan. Georgia Environmental Protection Division. <http:// www.georgiawaterplanning.org/>.

Henriksen, J.A., Heasley, J., Kennen, J.G., Nieswand, S., 2006. Users' Manual for the Hydroecological Integrity Assessment Process software (Including the New Jersey Assessment Tools). US Geological Survey Report 2006-1093. <http:// www.fort.usgs.gov/Resources/Research_Briefs/HIP.asp>

Jackson, D.A., 1993. Stopping rules in principal components-analysis - a comparison of heuristic and statistical approaches. Ecology 74, 2204-2214.

Jain, A.K., 2010. Data clustering: 50 years beyond $k$-means. Pattern Recogn. Lett. 31, 651-666.

Jenks, G.F., 1967. The data model concept in statistical mapping. Int. Yearb. Cartogr. 7, 186-190.

Kennard, M.J., Mackay, S.J., Pusey, B.J., Olden, J.D., Marsh, N., 2010a. Quantifying uncertainty in estimation of hydrologic metrics for ecohydrological studies. River Res. Appl. 26, 137-156.

Kennard, M.J., Pusey, B.J., Olden, J.D., Mackay, S.J., Stein, J.L., Marsh, N., 2010b. Classification of natural flow regimes in Australia to support environmental flow management. Freshw. Biol. 55, 171-193.

Kennen, J.G., Hendriksen, J.A., Nieswand, S.P., 2007. Development of the Hydroecological Integrity Assessment Process for Determining Environmental Flows for New Jersey Streams. US Geological Survey Scientific Investigations Report 2007-5206.

Kennen, J.G., Hendriksen, J.A., Heasley, J., Cade, B.S., Terrell, J.W., 2009. Application of the Hyroecological Integrity Assessment Process for Missouri streams. US Geological Survey Scientific Investigations Report 2009-1138.

Kenny, J.F., Barber, N.L., Hutson, S.S., Linsey, K.S., Lovelace, J.K., Maupin, M.A., 2009 Estimated Use of Water in the United States in 2005: U.S. Geological Survey Circular 1344.

Knight, R.R., Gregory, M.B., Wales, A.K., 2008. Relating streamflow characteristics to specialized insectivores in the Tennessee River Valley: a regional approach. Ecohydrology 1, 394-407.

Leopold, L.B., 1994. A View of the River. Harvard University Press, Cambridge, MA.

Magilligan, F.J., Nislow, K.H., 2001. Long-term changes in regional hydrologic regime following impoundment in a humid-climate watershed. J. Am. Water Resour. Assoc. 37, 1551-1569.

Magilligan, F.J., Nislow, K.H., 2005. Changes in hydrologic regime by dams. Geomorphology 71, 61-78.

Mathews, R., Richter, B.D., 2007. Application of the indicators of hydrologic alteration software in environmental flow setting. J. Am. Water Resour. Assoc. 436, 1400-1413.

McManamay, R.A., Orth, D.J., Dolloff, C.A., Frimpong, E.A., 2011a. A regional classification of unregulated streamflows: spatial resolution and hierarchical frameworks. River Res. Appl. doi:10.1002/rra.1493.
McManamay, R.A., Orth, D.J., Dolloff, C.A., Frimpong, E.A., 2011b. Regional frameworks applied to hydrology: can landscape-based frameworks capture the hydrologic variability? River Res. Appl. doi:10.1002/rra.1535.

Mohamoud, Y.M., 2008. Prediction of daily flow duration curves and streamflow for ungaged catchments using regional flow duration curves. Hydrol. Sci. 53, 706724

Moyle, P.B., Mount, J.F., 2007. Homogenous rivers, homogenous fauna. Proc. Natl. Acad. Sci. U.S.A. 104, 5711-5712.

North Carolina Department of Environment and Natural Resources (NCDENR), 2001. North Carolina State Water Supply Plan. Division of Water Resources. <http:// www.ncwater.org>.

Olden, J.D., Poff, N.L., 2003. Redundancy and the choice of hydrologic indices for characterizing streamflow regimes. River Res. Appl. 19, 101-121.

Olden, J.D., Kennard, M.J., Pusey, B.J., 2011. A unifying framework to hydrologic classification with a review of methodologies and applications in ecohydrology. Ecohydrology, in press. doi:10.1002/eco.251.

Pillai, K.C., 1955. Some new test criteria in multivariate analysis. Ann. Math. Stat. 26, 117-121.

Poff, N.L., 1996. A hydrogeography of unregulated streams in the United States and an examination of scale-dependence in some hydrological descriptors. Freshw. Biol. 36, 71-91.

Poff, N.L., Ward, J.V., 1989. Implications of streamflow variability and predictability for lotic community structure - a regional-analysis of streamflow patterns. Can. J. Fish. Aquat. Sci. 46, 1805-1818.

Poff, N.L., Zimmerman, J.Z.H., 2010. Ecological responses to altered flow regimes: a literature review to inform the science and management of environmental flows. Freshw. Biol. 55, 194-205.

Poff, N.L., Allan, J.D., Bain, M.B., Karr, J.R., Prestegaard, K.L., Richter, B.D., Sparks, R.E., Stromberg, J.C., 1997. The natural flow regime: a paradigm for river conservation and restoration. BioScience 47, 769-784.

Poff, N.L., Bledsoe, B.P., Cuhaciyan, C.O., 2006a. Hydrologic variation with land use across the contiguous United States: geomorphic and ecological consequences for stream ecosystems. Geomorphology 79, 264-285.

Poff, N.L., Olden, J.D., Pepin, D.M., Bledsoe, B.P., 2006b. Placing global stream flow variability in geographic and geomorphic contexts. River Res. Appl. 22, 149166.

Poff, N.L., Olden, J.D., Merritt, D.M., Pepin, D.M., 2007. Homogenization of regional river dynamics by dams and global biodiversity implications. Proc. Natl. Acad. Sci. U.S.A 104, 5732-5737.

Poff, N.L., Richter, B.D., Arthington, A.H., Bunn, S.E., Naiman, RJ., Kendy, E., Acreman, M., Apse, C., Bledsoe, B.P., Freeman, M.C., Henriksen, J., Jacobson, R.B., Kennen, J.G., Merritt, D.M., O'Keeffe, J.H., Olden, J.D., Rogers, K., Tharme, R.E., Warner, A., 2010. The ecological limits of hydrologic alteration (ELOHA): a new framework for developing regional environmental flow standards. Freshw. Biol. 55, 147170.

Pyron, M., Neumann, K., 2008. Hydrologic alterations in the Wabash River watershed, USA. River Res. Appl. 24, 1175-1184.

Richhter, B.D., Baumgartner, J.V., Powell, J., Braun, D.P., 1996. A method for assessing hydrologic alteration within ecosystems. Cons. Biol. 10, 1163-1174.

Richter, B.D., 2010. Re-thinking environmental flows: from allocations and reserves to sustainability boundaries. River Res. Appl. 26, 1052-1063.

Sanborn, S.C., Bledsoe, B.P., 2006. Predicting streamflow regime metrics for ungaged streams in Colorado, Washington, and Oregon. J. Hydrol. 325, 241-261.

SAS, 2008. JMP Statistics and Graphics Guide, Release 8. SAS Institute Inc, Cary, NC.

Sun, G., McNulty, S.G., Myers, J.A.M., Cohen, E.C., 2008. Impacts of multiple stresses on water demand and supply across the Southeastern United States. J. Am. Water Resour. Assoc. 44, 1441-1457.

Trush, W.J., McBain, S.M., Leopold, L.B., 2000. Attributes of an alluvial river and their relation to water policy and management. Proc. Nal. Acad. Sci. U.S.A. 97, 1185811863.

Turton, D., Fisher, B., Seilheimer, T.S., Esralew, R., 2008. An Assessment of Environmental Flows for Oklahoma. US Geological Survey Report 20080K107B.

US Army Corps of Engineers (USACE), 2011. Corps Map. National Inventory of Dams. US Army Corps of Engineers. <https://nid.usace.army.mil>.

Vitousek, P.M., Mooney, H.A., Lubchenco, J., Melillo, J.M., 1997. Human domination of Earth's ecosystems. Science 277, 494-499.

Vogel, R.M., Wilson, I., 1996. Probability distribution of annual maximum, mean, and minimum streamflows in the United States. J. Hydrol. Eng. 1, 69-76.

Vogl, A.L., Lopes, V.L., 2009. Impacts of water resources development on flow regimes in the Brazos River. Environ. Monit. Assess. 157, 331-345.

Ward, J.V., Stanford, J.A., 1983. The serial discontinuity concept of lotic ecosystems. In: Fontaine, T.D., III, Bartell, S.M. (Eds.), The Dynamics of Lotic Ecosystems. Ann Arbor Science, Ann Arbor, pp. 29-42.

Wilks, S.S., 1932. Certain generalizations in the analysis of variance. Biometrika 24, 471-494.

Wollock, D.M., Winter, T.C., McMahon, G., 2004. Delineation and evaluation of hydrologic landscape regions in the United States using geographic information system tools and multivariate statistical analyses. Environ. Manage. 34, 71-88. Zar, J.H., 1999. Biostatistical Analysis, fourth ed. Prentice Hall, NJ.

Zhu, Y., Day, R.L., 2009. Regression modeling of streamflow, baseflow, and runoff using geographic information systems. J. Environ. Manage. 90, 946-953. 